OPEN ACCESS

Edited by:

Harikumar KB,

Rajiv Gandhi Centre for Biotechnology,

India

Reviewed by:

Lekshmi R Nath

Amrita College of Pharmacy, India

Federica Sangiuolo,

University of Rome Tor Vergata, Italy

Alexander Akhmedov,

University of Zurich, Switzerland

*Correspondence:

Li Qin

lqin@hnucm.edu.cn

${ }^{\dagger}$ These authors have contributed equally to this work

Specialty section:

This article was submitted to

Cancer Molecular Targets

and Therapeutics,

a section of the journa

Frontiers in Oncology

Received: 28 October 2021 Accepted: 12 January 2022

Published: 16 February 2022

Citation:

Deng CF, Zhu N, Zhao TJ, Li HF, Gu J, Liao DF and Qin L (2022)

Involvement of $L D L$ and $O x-L D L$

in Cancer Development and

Its Therapeutical Potential.

Front. Oncol. 12:803473.

doi: 10.3389/fonc. 2022.803473

\section{Involvement of LDL and ox-LDL in Cancer Development and Its Therapeutical Potential}

\author{
Chang-Feng Deng ${ }^{1 \dagger}$, Neng Zhu ${ }^{2 \dagger}$, Tan-Jun Zhao ${ }^{1}$, Hong-Fang $\mathrm{Li}^{1}$, Jia Gu ${ }^{1}$, \\ Duan-Fang Liao ${ }^{1}$ and Li Qin ${ }^{1,3 \star}$
}

${ }^{1}$ Division of Stem Cell Regulation and Application, School of Pharmacy, Hunan University of Chinese Medicine, Changsha, China, ${ }^{2}$ Department of Urology, The First Hospital of Hunan University of Chinese Medicine, Changsha, China, ${ }^{3}$ Institutional Key Laboratory of Vascular Biology and Translational Medicine in Hunan Province, Hunan University of Chinese Medicine, Changsha, China

Lipid metabolism disorder is related to an increased risk of tumorigenesis and is involved in the rapid growth of cancer cells as well as the formation of metastatic lesions. Epidemiological studies have demonstrated that low-density lipoprotein (LDL) and oxidized low-density lipoprotein (ox-LDL) are closely associated with breast cancer, colorectal cancer, pancreatic cancer, and other malignancies, suggesting that LDL and ox-LDL play important roles during the occurrence and development of cancers. LDL can deliver cholesterol into cancer cells after binding to LDL receptor (LDLR). Activation of $\mathrm{PI} 3 \mathrm{~K} / \mathrm{Akt} / \mathrm{mTOR}$ signaling pathway induces transcription of the sterol regulatory elementbinding proteins (SREBPs), which subsequently promotes cholesterol uptake and synthesis to meet the demand of cancer cells. Ox-LDL binds to the lectin-like oxidized low-density lipoprotein receptor-1 (LOX-1) and cluster of differentiation 36 (CD36) to induce mutations, resulting in inflammation, cell proliferation, and metastasis of cancer. Classic lipid-lowering drugs, statins, have been shown to reduce LDL levels in certain types of cancer. As LDL and ox-LDL play complicated roles in cancers, the potential therapeutic effect of targeting lipid metabolism in cancer therapy warrants more investigation.

Keywords: tumorigenesis, cancer development, LDL, ox-LDL, statins

\section{INTRODUCTION}

Cholesterol is an indispensable component of life, and the intracellular cholesterol levels are maintained through a series of factors, including cholesterol synthesis, uptake, efflux, esterification, metabolism, and transportation (1). Epidemiological studies have shown that cholesterol plays a vital role in the occurrence and development of cancer, and high plasma cholesterol levels are 
positively correlated with the death risk of certain cancer types (2). It has been reported that every $10 \mathrm{mg} / \mathrm{dL}$ increase in cholesterol increases the risk of recurrence of prostate cancer by $9 \%$ (3). With the rapid proliferation of tumors, cancer cells need large amount of cholesterol to meet membrane biogenesis and biofunctional requirements (4). Statins mainly exert lipidlowering effect through mevalonate pathway. Studies have shown that inhibition of mevalonate pathway can down-regulate the expression of farnesyl pyrophosphate (FPP) and geranylgeranyl pyrophosphate (GGPP) isoprenyls, the isoprenyl group is critical in modifying $G$ proteins involved in cancer cell proliferation, migration, and survival (5). Various studies support the positive roles of statins in human cancer suppression or patient's prognosis (6-8), and the statin users' cancer-related mortality and recurrence rate are significantly reduced (8).

In the process of tumorigenesis and progression, cancer cells exhibit metabolic abnormalities to meet the elevated energy and biosynthetic demands associated with the rapid growth of tumors (9). It is worth mentioning that cholesterol is the precursor for steroid hormones, bile acids, vitamin $\mathrm{D}$, and oxysterols, and acts as a key material for cell growth (10). Low-density lipoprotein (LDL) is a critical lipoprotein and carrier of cholesterol mediating the transfer of cholesterol from the liver to peripheral tissues (11). When cellular cholesterol levels decrease, the expression of LDL receptor (LDLR) increases, and the extracellular domain of LDLR can bind to circulating LDL and promote its uptake through endocytosis. After entering the cell, LDL will be delivered to the lysosome. LDL is hydrolyzed by lipases, and then free cholesterol is released for cell utilization (12). Recently, LDLR has been found to be over-expressed in various cancers such as hepatocellular carcinoma (HCC), lung cancer, breast cancer, colorectal cancer, prostate cancer, and so on (13-15). Since cancer cells require more cholesterol to obtain energy than normal cells, they may raise their cholesterol levels through receptor-mediated endocytosis of LDL (16). Abnormal lipid metabolism can produce lipotoxicity that induces oxidative stress, which can significantly increase reactive oxygen species (ROS) levels (17), Gradual increase in oxidative stress can lead to the oxidation of

\footnotetext{
Abbreviations: ABCA1, ATP binding cassette transporters A1; ABCG1, ATP binding cassette transporters G1; ACAT-1, coenzyme a-cholesterol acyltransferase-1; BMI, Body mass index; ccRCC, clear cell renal carcinoma; CD36, cluster of differentiation 36; CDHR, cadherin-related family member3; CT1, carditorphin 1; EMT, Epithelial mesenchymal transformation; ER, estrogen receptor; FAK1, focal adhesion kinase 1; FPP, farnesyl pyrophosphate; GGPP, geranylgeranyl pyrophosphate; GWAS, genome-wide association studies; HCC, hepatocellular carcinoma; HER2, epidermal growth factor receptor 2; HIF-1 $\alpha$, hypoxia-Inducible factor 1-Alpha; HMGA2, high mobility group AT-hook 2; HMGCR, 3-hydroxy-3-methylglutaryl coenzyme A reductase; LDL, low-density lipoprotein; LDL-C, LDL-cholesterol; LDLR, LDL receptor; LOX-1, lectin-like oxidized low-density lipoprotein receptor-1; LXR, liver X Receptor; miR-155, microRNA155; miR-210, microRNA-210; MMPs, matrix metalloproteinases; NF$\kappa \mathrm{B}$, nuclear factor kappa-B; OS, overall survival; ox-LDL, oxidized low-density lipoprotein; PCSK9, proprotein convertase subtilisin/kexin type 9; POX, proline oxidase; PR, progesterone receptor; PSA, prostate-specific antigen; RAC1, Rasrelated C3 botulinum toxin substrate 1; RNS, reactive nitrogen species; ROS, radical oxygen species; SPRED2, sprout-related EVH1 domain 2; SQLE, squalene epoxidase; SREBP, sterol regulatory element-binding proteins; SRs, scavenger receptors; TKI, tyrosine kinase inhibitor; TNM, tumor node metastases; VEGF, vascular endothelial growth factor.
}

intracellular LDL to oxidized low-density lipoproteins (ox-LDL). Besides, oxidative stress promotes DNA damages in cancers, which further results in malignant transformation and carcinogenesis $(18,19)$. Elevated plasma ox-LDL has been detected in breast cancer, gastric cancer, and colon cancer (20, 21). Since different types of cancer present different lipid disorders, the lipid may play versatile roles according to the types of cancer (22). Therefore, LDL and ox-LDL may have variable effects during cancer development (Figure 1).

\section{LDL and ox-LDL in Lipid Homeostasis}

LDL is a complex particle containing proteins and lipids, and its outermost layer is surrounded by a lipid core and monomeric protein ApoB-100 (23). Cholesterol synthesized by the liver is transported to cells throughout the body by LDL, and about $70 \%$ of LDL-cholesterol (LDL-C) in plasma is degraded by LDLRmediated endocytosis (24). LDLR activity is the primary factor determining circulating LDL levels. Due to its critical role in cholesterol homeostasis, LDLR mediates various signaling transduction in hepatocytes. Moreover, sterol regulatory element-binding proteins (SREBPs) are transcription factors for cholesterol production and absorption, and they regulate one of the critical transcription pathways involved in cholesterol homeostasis $(25,26)$. LDLR and several enzymes related to cholesterol synthesis, including recombinant 3-hydroxy-3methylglutaryl coenzyme A reductase (HMGCR) and squalene epoxidase (SQLE), are directly regulated by SREBP (9). Once LDL is endocytosed, it fuses with lysosomes and then is hydrolyzed in the lysosome to release cholesterol, fatty acids, and amino acids. When cellular cholesterol levels are low, SREBP2 is cleaved and transferred to the nucleus, where it upregulates the expression of LDLR; when cellular cholesterol levels are high, SREBP2 remains inactive, and LDLR expression is down-regulated $(27,28)$. Proprotein convertase subtilisin/kexin type 9 (PCSK9) is another key regulator of LDLR. PCSK9, as a liver protease, can promote the degradation of hepatic LDL receptors, leading to increased LDL-C levels (29-31). Up to date, PCSK9 inhibitors evolocumab and alirocumab have been successfully applied to reduce circulating LDL-C levels (32). Excessive intracellular cholesterol can be esterified by acylcoenzyme A (cholesterol acyltransferases) and stored in lipid droplets. Meanwhile, it can also be transported to the blood through ATP binding cassette transporters A1 (ABCA1) or ATP binding cassette transporters G1 (ABCG1), both ABCA1 and ABCG1 are transcriptionally regulated by the Liver X Receptor (LXR) (33). LXR helps maintain cholesterol homeostasis not only through promotion of cholesterol efflux but also through suppression of LDL uptake by enhancing E3 ubiquitin ligase activity and mediating LDLR degradation (34).

LDL contains polyunsaturated fatty acids, which can be oxidized by ROS and reactive nitrogen species (RNS) to generate lipid peroxides, such as ox-LDL. Whereas ox-LDL, in turn, stimulates ROS production (35). ApoB-100 is the protein component of LDL, as well as a high-affinity ligand for LDLR (36). Cysteine, lysine, histidine, and tyrosine residues in ApoB100 are also the oxidation targets of ROS and RNS, and the oxidative modification of ApoB-100 may abrogate its function as 


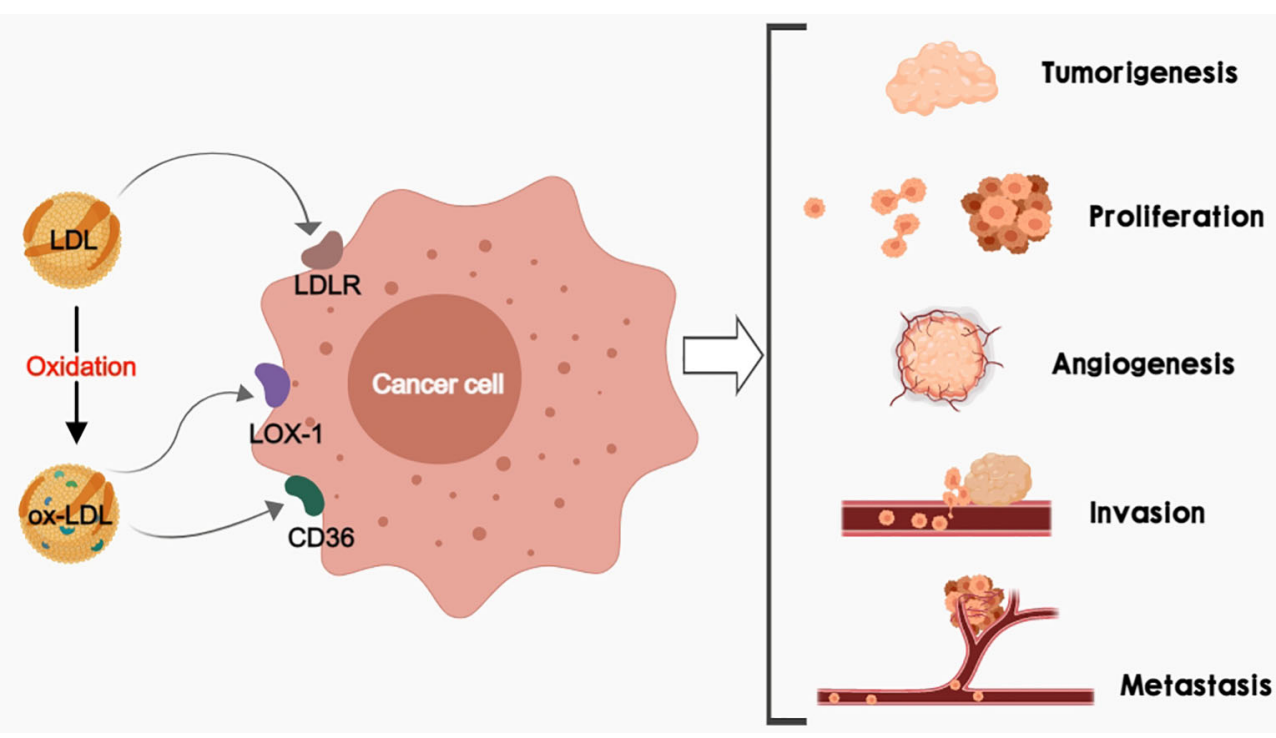

FIGURE 1 | LDL and/or ox-LDL bind to their receptors (LDLR, LOX-1, and CD36) respectively to promote tumorigenesis, cancer cell proliferation, cancer angiogenesis, as well as cancer invasion and metastasis.

an LDLR ligand (37). Once ox-LDL is no longer recognized by LDLR, it may be identified and combined with scavenger receptors (SRs) such as lectin-like oxidized low-density lipoprotein receptor-1 (LOX-1), scavenger receptor A (SR-A), and cluster of differentiation 36 (CD36). Ox-LDL is a wellknown biomarker for cardiovascular diseases, and it enhances endothelial cell adhesion by activating oxidative stress and stimulates the expression of pro-inflammatory factors and adhesion molecules, as well as chemokines in vascular endothelial cells, leading to endothelial dysfunction (38). In recent years, more and more studies have focused on ox-LDL and cancers, and it has been found that the elevated levels of oxLDL, as well as LOX-1 and CD36, are related to the increased risk of various cancers. Ox-LDL promotes epithelial-mesenchymal growth, cytoplasmic transformation, induces protective autophagy, activates inflammasomes, and the promotes release of growth factors, cytokines, and other pro-inflammatory markers to stimulate oncogenic signals, resulting in cell mutations and chemotherapy resistance (39).

\section{LDL and ox-LDL in Cancer Development}

Alterations in blood cholesterol levels (decreased or increased) are critical phenomena in many malignancies (2). Hyperlipidemia has been shown to increase the risk of cancer (40), and cancer cells tend to accumulate a high amount of cholesterol either by up-regulating cholesterol biosynthesis or by enhancing cholesterol uptake for rapid cancer development (41). Increased intracellular cholesterol content has been observed in the tissues of breast cancer, ovarian cancer, and renal cancer $(42,43)$. Overproduction of LDLR is an important mechanism for cancer cells to obtain more essential fatty acids through LDLR endocytosis. It has been found that the up-regulation of LDLR can promote the rapid uptake of LDL in most cancers. The expression of LDLR is affected by feedback regulation of LDL-C levels in normal human prostate cells, while this feedback regulation is commonly lost in prostatic cancer cells (44).

Epithelial mesenchymal transformation (EMT) is a process of losing epithelial apical-basal polarity and cell-cell adhesion and transiting to invasive mesenchymal cells. After EMT, cells possess a number of malignant properties to carcinoma cells, including invasive behavior, stemness, and greater resistance to chemotherapy and immunotherapy (45). Many EMT transcription factors are regulated by PI3K/Akt and ERK signaling pathways to promote cancer cell proliferation and migration (46). In addition, PI3K/Akt regulates cancer cell growth by activating mTOR, which may promote cholesterol synthesis and uptake by activating SERBP. STAT3 activation is associated with transcription of genes involved in cell proliferation, migration, and survival, as well as increased expression of vascular endothelial growth factor (VEGF) and matrix metalloproteinases (MMPs) that favor angiogenesis (47). Preclinical studies have highlighted the importance of LDL in supporting the growth and proliferation of different cancer types by tuning numerous signaling pathways (PI3K/Akt, ERK, STAT3, etc.) (48-50). Alternatively, with high LDL levels, tumors may evade immune surveillance; LDL has been shown to limit the antitumor therapeutic effect of human $\gamma \delta \mathrm{T}$ cells in vivo, thereby enhancing tumor metastasis (51). In line with the results, chronic lymphocytic leukemia patients show a high incidence of elevated LDL cholesterol and their survival rates have improved after treatment with statins (52). Clinical data have shown that higher levels of cholesterol and LDL are associated with lower overall survival (OS) of patients treated with anti-PD1/L1 (53). Moreover, LDL cholesterol promotes the lymph node metastasis of colon cancer cells by inducing the activation of microvascular endothelial cells (54). It is also worth 
noting that LDL has been found to enhance cell stemness (55). Overall, these studies reveal that LDL has deleterious effects on cancer development (Figure 2).

Elevated levels of ox-LDL are a significant feature of lipid metabolism disorders and inflammation and have been implicated in many aspects of cancer, ox-LDL has been shown to induce mutagenesis, stimulate proliferation, induce autophagy, and initiate metastasis. For example, Esterbauer et al. showed that components of ox-LDL such as 4hydroxynonenal could stimulate primary rat hepatocytes mutagenesis in vitro (56). In addition, ox-LDL can potentially contribute to the induction of cancer by increasing the expression of microRNA-210 (miR-210) (57). Ox-LDL upregulates hypoxia-inducible factor- $\alpha$ (HIF- $\alpha$ ) expression and increases miR-210 expression, which leads to downregulation of sprout-related EVH1 domain 2 (SPRED2), a protein that reduces cell migration, leading to a higher risk of cancer and vascular diseases (58). Other studies have shown that administration of ox-LDL increases the proliferation of patient-derived glioblastoma xenografts and ovarian carcinoma cells $(59,60)$. These data support an effect of ox-LDL on promoting tumor growth.

Autophagy is an evolutionarily conserved intracellular selfdefense mechanism, and organelles and proteins are degraded into autophagy bubbles through fusion with lysosomes. Cells thereby prevent the toxic accumulation of damaged or unnecessary components, but also recycle these components to sustain metabolic homoeostasis (61). Recent studies suggest that autophagy is a powerful survival strategy for cancer cells, by recycling intracellular components in conditions of metabolic stress or during anticancer treatments (62). Autophagy is an important mechanism for ox-LDL to participate in cancer progression. Ox-LDL activates the key metabolic enzyme oproline oxidase (POX) and promotes cancer cell autophagy through the mechanism related to ox-LDL and PPAR $\gamma$. This study also found that the effect of POX on autophagy was achieved by producing superoxide that took effects by regulating beclin-1 (63). Another study showed that ox-LDL was capable of inducing autophagy in part through activation of microRNA155 (miR-155) in HUVEC cells (64). By activating autophagy, cancer cells undergoing EMT can gain resistance to cell death as a strategy for survival when spreading outside the tumor mass (65).

Recent evidence suggests that as specific receptors for oxLDL, CD36, LOX-1 are upregulated in and contribute to the pathophysiology of dyslipidemia-related diseases, such as cardiovascular disease and obesity $(66,67)$. Studies have found that LOX-1 is upregulated and promotes tumor development in

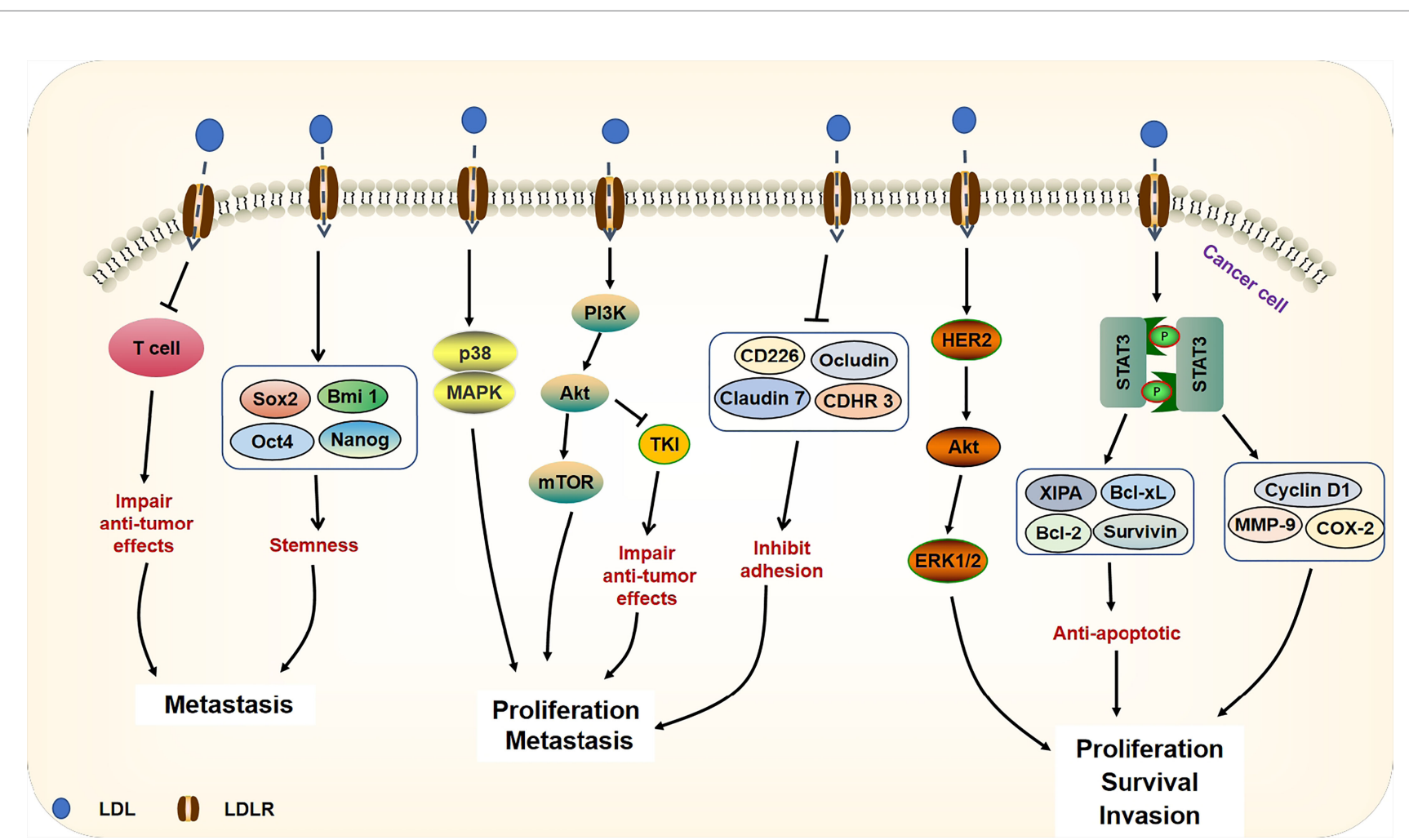

FIGURE 2 | Signaling pathways of LDL on cancer progression. The accumulation of LDL can damage the anti-tumor effects of T cells. Through up-regulating the expressions of stemness genes (Sox2, Bmi 1, Oct4, Nanog), LDL supports cancer metastasis. LDL activates p38 and MAPK as well as PI3K/AKt/mTOR signaling pathways, leading to cancer proliferation and metastasis. Besides, through activation of PI3K/AKt signaling, LDL compromises the TKI anti-tumor efficacy against cancer cells. LDL decreases adhesion molecules (CD226, Ocludin, Claudin 7, CDHR3), which help cell migration. Moreover, LDL can activate HER2/Akt/ERK signaling pathway and up-regulate STAT3 target genes (including anti-apoptotic genes and MMP-9, Cyclin D1, COX-2) expression, which promote the survival and invasion of cancer cells. 
different cancers such as breast cancer, colorectal cancer, and ovarian cancer. Together, the combination of ox-LDL and LOX1 stimulates ROS production, which leads to oxidative DNA damage (39). Besides, it can promote cancer cell proliferation, invasion, and angiogenesis by activating nuclear factor kappa-B $(\mathrm{NF}-\mathrm{\kappa B})$ and up-regulating the expression of VEGF, MMP-2, and $M M P-9(20,39)$. The scavenging receptor CD36, a scavenger receptor for ox-LDL, is found to be highly expressed in multiple cell types and mediates lipid uptake, immunological recognition, inflammation, molecular adhesion, and apoptosis (68). Furthermore, addition of ox-LDL has been shown to stimulate the proliferation of glioblastoma patient-derived xenografts, whereas siRNA-mediated knockdown of CD36 resulted in reduced proliferation. Ox-LDL is internalized by CD36 and the accumulation of ox-LDL and oxysterol metabolites can lead to overexpression of carditorphin 1(CT-1), which subsequently promotes inflammation, proliferation, and angiogenesis (60). Park et al. showed that the binding of ox-LDL to CD36 enhanced the activation of focal adhesion kinase 1 (FAK1) and Ras-related C3 botulinum toxin substrate 1 (RAC1) (69), which might be in part responsible for the cellular morphological changes necessary for the initiation of EMT, including loss of polarity and actin polymerization (70). As an important signal membrane transporter, CD36 is involved in the uptake of oxLDL and binds with ox-LDL to participate in EMT signal transduction. All of these effects are shown in Figure 3.

\section{DISSECTING THE ROLES OF LDL AND OX-LDL IN PARTICULAR TYPES OF CANCERS}

\section{LDL and ox-LDL in Breast Cancer}

Breast cancer is the second leading cause of cancer-related deaths in females (71). Breast cancer is a heterogeneous disease, with major subtypes defined by expression of estrogen receptor (ER), progesterone receptor (PR), and epidermal growth factor receptor 2 (HER2) receptor (72). The major subtypes are as follows: luminal (ER-positive), HER2-like (mainly ER-negative and HER2-positive), and basal-like (mainly ER-negative, PRnegative, and triple-negative). The HER2-like and basal-like are the most aggressive and these subtypes are often used to predict prognosis and treatment responses (73).

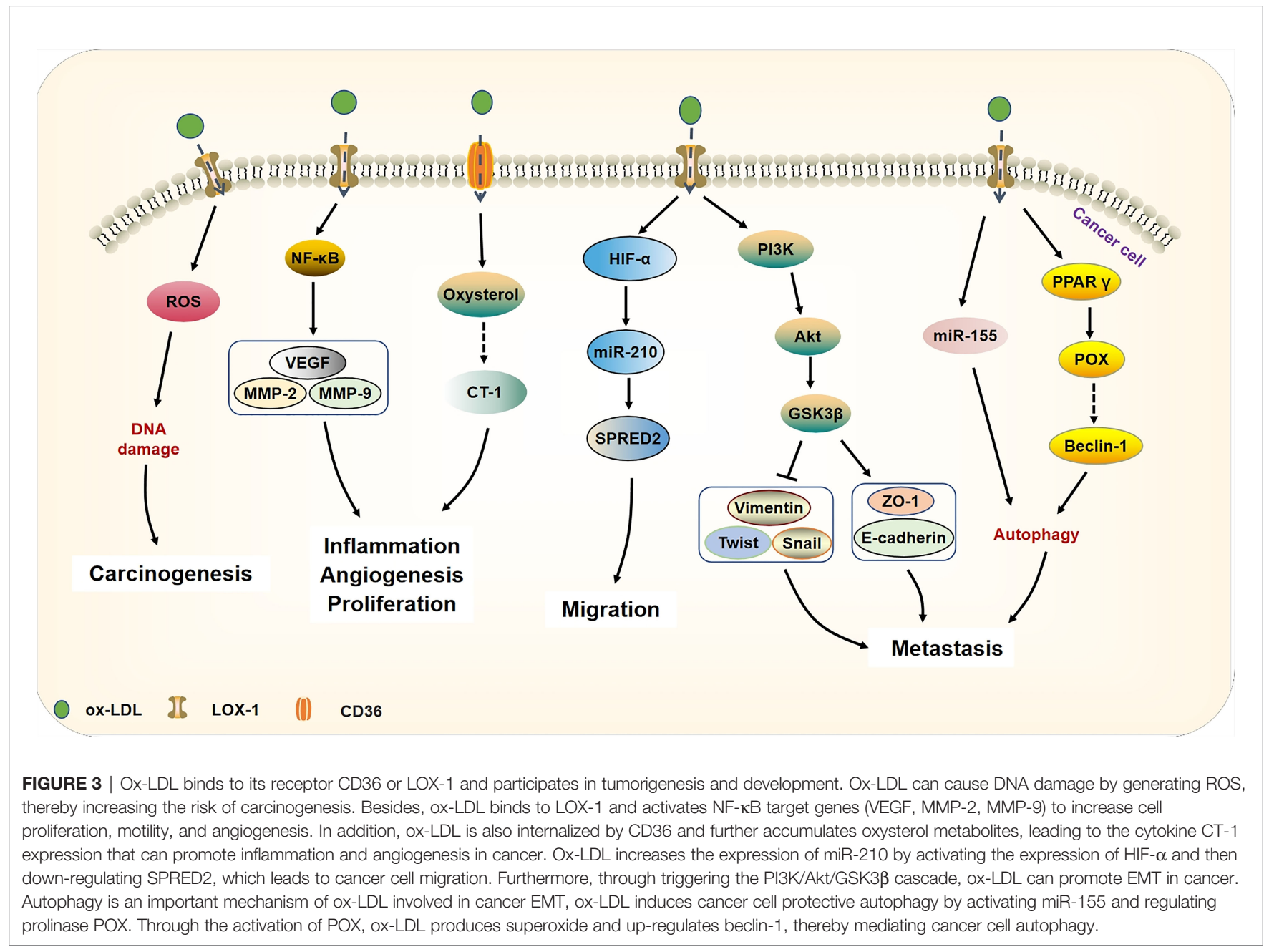


A positive correlation between LDL-C and breast cancer progression has been observed. A prospective study in Portugal showed that plasma LDL-C levels were positively correlated with the tumor volume, breast cancer patients with higher levels of LDL-C at diagnosis have larger tumors, higher differentiation grade, and proliferative rate (74). Two Mendelian randomized studies support the finding that the increased plasma LDL-C is associated with a higher risk for breast cancer $(75,76)$. In contrast, two studies found that LDL-C was negatively associated with breast cancer risk $(77,78)$. Confounding factors such as region, diet, and comorbidities, as well as individual researchers' biases in the selection of populations and measurement methods, might have contributed the differences in clinical studies (79).

The LDL-C exerts its effects on breast cancer cells through a variety of mechanisms. LDL promotes the proliferation and migration of ER-negative cell lines, but not ER-positive cancer cells. LDL-C can also induce the proliferation of the HER2positive breast cancer cell line BT-474 (48). Clinicopathological studies have shown that with the increase in LDLR and acyl coenzyme a-cholesterol acyltransferase-1 (ACAT-1), the accumulation of cholesterol ester increases accompanied by the advancement of tumor grade (80). The increased LDL-C internalization and esterification may explain these differences in HER2-like or triple-negative breast cancer cells. They present with increased expression of LDLR and increased expression and activity of ACAT-1, which lead to a more remarkable ability to absorb, store, and utilize exogenous cholesterol in cells (81). A potential mechanism for LDL-promoted breast tumorigenesis is to increase phosphorylation of oncogenic signaling pathways, Akt and ERK via activating HER2 (48, 82). LDL also promotes the progression and metastasis of breast cancer through Akt-induced EMT and angiogenesis, increases the levels of mesenchymal markers Slug, vimentin, and $\beta$ catenin, and decreases in expression of adhesion molecules (cadherin-related family member3(CDHR), CD226, Claudin 7 and Ocludin), thereby promoting the migration and invasion of breast cancer cells $(48,83)$. Beyond in vitro studies, Gallagher et al. found that elevated LDLR expression in tumor accelerated LDL-C-mediated breast cancer growth in hyperlipidemic mice, In contrast, LDLR silencing and lower circulating levels of LDL$\mathrm{C}$ retard tumor growth in HER2 positive and triple-negative breast cancer mouse models (84). So far, ample studies have emphasized the importance of LDL in breast cancer occurrence and development.

It has been found that elevated levels of ox-LDL are detected in the plasma of breast cancer patients, and the elevated plasma oxLDL levels are positively correlated with the increase of breast cancer risk $(85,86)$. In addition, as the main receptor for internalization of ox-LDL, LOX-1 is overexpressed in $70 \%$ of human breast cancers and has been shown to be positively correlated with tumor grade and stage (87). Ox-LDL promotes the proliferation of the non-tumorigenic mammary epithelial cell line MCF10A cells and up-regulates the pro-inflammatory signals. Concretely, ox-LDL stimulates the proliferation of breast cancer cells via miR-21 in a dose-dependent manner, thereby activating the PI3K/Akt signaling pathways (88). Additionally, hominoidspecific oncogene, TBC1D3, a protein that regulates migration of human breast cancer cells have been found to up-regulate LOX-1 expression by activating the TNF $\alpha / N F-\kappa B$ signaling. Ox-LDL binds to LOX-1 and activates inflammatory pathways through NF- $\mathrm{KB}$, leading to transformation $(13,88)$. In contrast, depletion of LOX-1 by siRNA inhibits the invasion and migration of transformed breast mammary epithelial cells (13). Similarly, inhibition of LOX-1 by an antibody or a recombinant LOX-1 protein substantially suppresses the transendothelial migration of human breast cancer cells (8991). Furthermore, LOX- $1 \Delta 4$ is a splice variant of LOX-1 expressed in humans that lacks exon 4 (92). Due to the specific metabolic environment of different breast cancer phenotypes, LOX-1 and its splicing variant LOX-1 $\Delta 4$ may play a carcinogenic role in the specific regulation of expression patterns. A full understanding of LOX-1 and LOX-1 $\Delta 4$ molecular pathways in breast cancer may help develop a possible therapeutic option specific for different phenotypic cancer subtypes (87). As indicated above, a more indepth study of ox-LDL and LOX-1 as potential mediators for the cholesterol-breast cancer link should be performed.

\section{LDL and ox-LDL in Colorectal Cancer}

Recently, the field of cancer research has directed increased interest towards subsets of obesity-associated cancers. Specifically, data shows that in countries with high obesity prevalence, colorectal cancer incidence is high (93). Body mass index (BMI) is an important indicator of the survival of cancer patients, including colorectal cancer (94).

High levels of LDL-C are associated with increased colorectal cancer risk $(95,96)$, whereas the levels of free cholesterol and LDL-C in serum are found to be significantly lower in patients with lymph node metastasis than in patients without lymph node metastasis (97). Similarly, LDL-C acts as an independent prognostic factor for poor prognosis in metastatic colorectal cancer patients (98), and these results corroborate that higher LDL-C promotes distant metastasis in patients with colorectal cancer $(98,99)$. LDLR is essential for transporting serum LDL into cells. Several studies have evaluated the LDLR expression in colorectal cancer and have observed increased expression in colorectal cancer tissues, especially in colorectal cancer patients at stage $\mathrm{N}$ and $\mathrm{M}(55,100)$. Serum LDL-C levels in advanced cancer patients decreased due to the increased metabolic demands in cancer cells. Therefore, a decreased in blood cholesterol level in colorectal cancer patients may be a consequence of increased uptake of blood cholesterol by cancer cells; it is less likely to be a cause for colorectal cancer initiation (101). Study also showed that LDL could enhance stemness by increasing stemness-related genes, such as Sox2, Oct4, Nanog, and Bmil in colorectal cancer cells, increased ROS levels that can further activate MAPK pathways, and stimulated intestinal inflammation and colorectal cancer (55). Together, these studies hinted that LDL has deleterious results in colorectal cancer development.

A case study in Japan showed a significant positive association between elevated levels of plasma ox-LDL and risk of colorectal cancer (102). ox-LDL and oxidative stress may increase the risk of 
obesity-related colorectal cancer via NF- $\mathrm{BB}$ signaling and could be used as potential predictive and prognostic biomarkers for obesity complicated with colorectal cancer (103). Other research has found LOX-1 to be more directly linked to the risk of colorectal cancer compared to ox-LDL (104). One study on the involvement of LOX-1 in colorectal cancer has shown that LOX-1 expression is increased in $72 \%$ of human colon carcinomas, and overexpressed in $90 \%$ of highly aggressive and metastatic tumors (104). Furthermore, LOX-1 expression is positively correlated with cancer stage and grade than healthy counterparts (105). It is worth noting that a recent study reported that the serum sample and 100 tissue samples from 238 colorectal cancer patients showed high levels of LOX-1 compared with those who present low serum levels, high levels of LOX-1 determine a poorer OS and prognosis of patients. Therefore, LOX-1 may help in liquid biopsy detection and cancer diagnosis and treatment under the premise that cancerous tissues are not available (106). LOX-1 takes its effects in colorectal cancer via upregulating of VEGF-A165, HIF$1 \alpha$, and $\beta$-catenin, which are involved in cell migration and metastasis (107).

\section{LDL and ox-LDL in Pancreatic Cancer}

pancreatic cancer is one of the most devastating malignancies, with a 5-year OS rate of less than 5\% (108). Currently, treatment is dependent on surgical resection. However, only about $25 \%$ of pancreatic cancer patients are eligible for surgical resection due to pancreatic cancer invasion (109). Genome-wide association studies (GWAS) show that genetic factors are the primary risk factors related to pancreatic cancer; moreover, smoking, diabetes, drinking, obesity, chronic pancreatitis, and diet are all known risk factors for pancreatic cancer (110-112). A study found that genetically higher levels of LDL-C were associated with pancreatic cancer (113). As study showed that lipoprotein metabolic processes, in particular cholesterol uptake, are activated in the tumor. These metabolic processes increase the amount of cholesterol and the expression of LDLR in pancreatic tumor cells. Clinical data suggest that overexpressed LDLR is related to a high recurrence of pancreatic cancer $(114,115)$. High cholesterol intake is associated with an increased risk of pancreatic cancer (116), and knockdown of LDLR in patients' cells greatly reduces cholesterol uptake and alters its distribution, decreases cancer cell proliferation, and limits the activation of the ERK1/2 survival pathway. LDL-C can promote the proliferation of pancreatic cancer cells by activating the STAT3 pathway and upregulating the levels of oncogenes such as $B c l-2, B c l-x L$, survivin controlled by this transcription factor in pancreatic cancer cells (49). These findings suggest that LDLR can be a novel metabolic target in limiting patients progression $(114,115)$.

LOX-1 is overexpressed in pancreatic cancer tumors compared with adjacent normal tissues, stimulates the migration of pancreatic cancer cells and invasion of lymph nodes by inducing EMT, and has been associated with higher tumor node metastases (TNM) staging and poorer OS (117). Recent study has found that ox-LDL transforms into a glycolytic phenotype by promoting metabolism and inducing cytoprotective autophagy, thereby making pancreatic cancer cells resilient or resistant (118) LOX-1 can up-regulate the expression of $\mathrm{c}-\mathrm{Myc}$, and the transcription of high mobility group AT-hook 2 (HMGA2). HMGA2 is up-regulated in many cancers, which can regulate cell proliferation and differentiation, as well as promote metastasis (119). Furthermore, LOX-1 is associated with pancreatic cancer drug resistance, the long-chain non-coding RNA GSTM3TV2 can up-regulate LOX-1 and promote the resistance of pancreatic cancer cells to gemcitabine (120). These findings suggest the potential role of ox-LDL receptors in the development of pancreatic cancer.

\section{LDL and ox-LDL in Prostate Cancer}

Prostate cancer is the second most common malignancy worldwide in men (121). The growth of prostate cancer cells depends on the steroidal hormone androgen. Cholesterol is a common precursor of steroid hormones and plays a vital role in prostate differentiation and growth $(120,122)$. Epidemiological studies have shown strong or weak correlations between differences in plasma LDL-C concentration and the incidence of prostate cancer, though some are contradictory. Several studies failed to find any association between LDL-C and aggressive prostate cancer risk $(123,124)$, while a sizeable Mendelian randomization study showed a weak association between higher LDL-C levels and an increased risk of aggressive prostate cancer (125). In contrast, in another prospective study from the Netherlands, there is a positive association between prostate cancer risk and serum concentrations of LDL-C. Moreover, LDL-C is associated with higher cancer prevalence and more advanced tumor phenotypes $(122,126-128)$ These divergent results may be explained by the heterogeneity in the approaches used and significant differences in the follow-up of these studies.

Incubation of prostate cancer cells with LDL can significantly increase its proliferation, migration, and invasion (129). In addition, LDL-mediated effects on proliferation of prostate cancer cells are caused by PTEN loss and activation of Akt and ERK signaling pathways, and further activates SREBP, upregulating LDLR leading to cholesterol accumulation and cholesterol ester production (130). Moreover, LDL-C has been associated with higher cancer prevalence and more advanced tumor presentation. In the TRAMP mouse model, an autochthonous model of prostate cancer, hypercholesterolemia is shown to result in increased tumor volume and progression as well as increased tumor incidence and metastases to the lung (131). Furthermore, increased activation of de novo synthesis of cholesterol in tumor epithelial cells and influx of LDL from the surroundings tissues via LDL-R and SR-B1 promoted the bone metastasis of prostate cancer (132). It is noteworthy that normal cholesterol feedback of LDLR messages and protein is lost in prostate cancer (44). Because of the lack of LDLR feedback regulation, prostate cells obtain more essential fatty acids and increase prostaglandin 2 synthesis, leading to uncontrolled growth of prostate cancer cells (133). These studies suggest that prostate cancer may rely on cholesterol for metabolism and that low levels of LDL in cancer reflect the highly invasive nature of tumors. This suggests that LDLR may be an attractive therapeutic target for prostate cancer cells (134). 
Elevated plasma ox-LDL levels and LOX-1 expression may indicate advanced prostate cancer and lymph node metastasis. The cell signaling pathway in human prostate cancer cells (PC-3) treated with ox-LDL analyzed by phosphorylated protein chip is of importance. Ox-LDL can affect a variety of signaling pathways of PC-3 cells, including $\beta$-catenin, cMyc, NF- $\kappa B$, STAT1, STAT3, and apoptosis-related signaling pathways (including P27 and caspase-3), which affects the proliferation, migration, and invasion of prostate cancer cells, and in vitro experiments confirmed this (135). ox-LDL contributes to tumor progression through LOX-1 activation. Ox-LDL significantly triggers LOX-1 significantly and proportionally increases the expression of proangiogenic markers VEGF, MMP-2, and MMP-9, thereby promoting tumor metastasis (136). In addition, LOX-1 activated by ox-LDL reduces the expression of epithelial markers ( $E$ cadherin and plakoglobin) and the expression of mesenchymal markers (vimentin, $\mathrm{N}$-cadherin, snail, slug, etc), which lead to EMT that can further induce the invasion and migration of prostate cancer cells (20). All these observations suggest the use of ox-LDL and LOX-1 as a therapeutic target for prostate cancer.

\section{LDL and ox-LDL in Renal Cancer}

Renal cancer is a common type of human malignancies. Clear cell renal carcinoma (ccRCC) is the primary subtype of renal cancer, characterized by abnormal lipid accumulation of cholesterol, cholesterol esters and triglycerides (137). Although abnormal LDL level is related to increased cancer risk (138), the correlation between high LDL levels and renal cancer risk is not consistently observed in clinical studies. Several recent studies have focused on the relationship between LDL and renal cancer and have come to conflicting conclusions. Two studies reported that LDL is elevated in renal cancer and is positively associated with cancer risk $(138,139)$. While contrary to the results of the study conducted by Zhang et al. this could be explained by the fact that the data in control groups differed between the two studies, and the serum lipid levels in the Zhang et al. controls were much higher. Different dietary patterns and lifestyles in north and south China may account for the discrepancy (140). It has been proved by in vitro and in vivo experiments that LDL-C decreases the antitumor effect of tyrosine kinase inhibitor (TKI) on renal cancer and endothelial cells by activating the PI3K/Akt pathway (50). Surprisingly, low LDLR expression was found in renal cancer subtypes of ccRCC cells, while SR-BI expression was significantly increased. High cholesterol levels in ccRCC were partly related to SR-BI-mediated HDL uptake $(141,142)$. The results of large-scale clinical trials indicated a direct correlation between LDL-C and renal cancer risk, encouraging more basic research in the future to elucidate the potential mechanisms of those correlations.

There is not yet an epidemiological study examining ox-LDL and renal cancer, while in vitro analysis of ccRCC showed that LOX-1 is expressed both in the cytoplasm and in the nucleus (143). It is known that diet-induced hypercholesterolemia increases the expression of LOX-1 in renal arterioles, and subsequently facilitates the uptake and cytotoxicity effects of ox-LDL (144) Ox-LDL enhanced the LOX-1 expression in tubular epithelial cells in a dose-dependent manner within a certain concentration range and mediates EMT progression in rat renal tubular epithelial cells NRK-52E. Moreover, HK-2 cells derived from normal kidneys exposed to ROS at a non-cytotoxic level for a long term showed increased proliferation, anchored independent growth, and enhanced tumorigenicity in nude mice (145). These studies provide direct evidence for the malignant transformation of renal tubular epithelial cells induced by oxidative stress.

\section{LDL and ox-LDL in HCC}

HCC is the most prevalent cancer with a poor prognosis worldwide (146). Lipid seems to play a fundamental role in the development and progression of HCCs (147). As a key organ in lipid metabolism, liver is involved in the production of apolipoproteins, endogenous lipids and lipoproteins, which depend on the integrity of biofunctions of liver. Therefore, liver function in patients with HCC is significantly impaired, resulting in a distinctly abnormal patterns of serum lipids and lipoproteins (148). Multiple studies have shown that a decrease in both plasma HDL and LDL was slightly to significantly in HCC patients $(149,150)$. A large nationwide population-based study in South Korea showed that low lipid profile is an independent risk factor and preclinical marker of HCC (151). Similarly, in a report in Japan, low LDL was associated with increased mortality of HCC (152). However, there are some reports that the changes in lipoprotein levels and their prognostic significance in HCC are contradictory, and elevated LDL predicted a poorer prognosis for patients with HCC (153). Another study showed that low plasma HDL, high plasma LDL, and especially the combination of two, were significantly related to more aggressive HCC phenotype and the combination was significantly associated with a higher hazard ratio for death (154). There seems to be a two-way process because the presence of HCC is related to the aforementioned changes in plasma lipid. Low lipid profiles may reflect the degree of liver damage. When HCC occurs, the metabolism and synthesis of cholesterol are impaired, resulting in a decrease in plasma cholesterol levels (155). Meanwhile, the cancer cells increase cholesterol consumption to maintain faster proliferation, and changes in lipid content can alter HCC biological functions (154).

Previous study showed that serum cholesterol might promote the expression of VEGF, $M M P-2$, and $M M P-9$ by activating the $\mathrm{NF}-\mathrm{\kappa B}$ signaling pathway in HCC cells, indicating the proinflammatory effects of cholesterol (156). In non-alcoholic fatty liver disease mice, a high-fat diet can induce HCC. Following initiation of the obesogenic diet, the mice developed obesity, insulin resistance, hypertriglyceridemia, and elevated LDL-C, and eventually developed HCC $(157,158)$. Besides, LDLR and cholesteryl ester levels are higher in the murine HCC tissues (159). Similarity, as described in human HCCs, LDLR is also upregulated in cancer cells and stimulates cell proliferation (160).

Activation of oxidative stress is another key pathogenic mechanism. Plasma malondialdehyde and ox-LDL levels are significantly increased in HCC patients, and the oxidative stress was usually reversed after HCC resection (161). In addition, the uptake of ox-LDL via the CD36-Nogo-B-YAP pathway consequently drives the development of NAFLDassociated HCC (162). 


\section{LDL and ox-LDL in Ovarian Cancer}

Ovarian cancer is the most lethal gynecological malignancy in women. Patients with early ovarian cancer usually do not have cancer-specific symptoms, as a result, most are diagnosed with advanced ovarian cancer (163). Epidemiological studies of ovarian cancer risk and lipid levels are contradictory. A recent metaanalysis showed that the differences in plasma LDL-C between ovarian and non-ovarian cancer patients are not significant (164). In the Mendelian randomization analysis of 22,406 patients with invasive epithelial ovarian cancer, no association was found between the genetic variation that controls circulating LDL-C and the risk of epithelial ovarian cancer (165). While in a retrospective clinical study involving 1,550 ovarian cancer patients that assessed blood lipid characteristics, it was found that compared to the benign ovarian tumor group, levels of LDL-C and TC in the ovarian cancer group were significantly lowered (166). It should be noted that intracellular cholesterol levels were found to be elevated in high-grade serous ovarian cancer cells and malignant ascites (167). This might be explained by the highly malignant nature of ovarian cancer, which progresses quickly. Rapid tumor growth requires large amount of consumption of cholesterol and which subsequently leads to decreased plasma levels of LDL-C (168). Furthermore, ovarian cancer patients with a low blood cholesterol level at the time of diagnosis show improvement in blood cholesterol level after successful primary surgery and chemotherapy (169).

Clinical case-control studies suggest that plasma ox-LDL levels are associated with an increased breast and ovarian cancer risk. Ox-LDL is mitogenic to ovarian cancer cells. oxLDL at a dose of $0.1 \mu \mathrm{g} / \mathrm{mL}$ stimulates the proliferation of ovarian cancer cell lines CAOV3 and SKOV3 and reduces the sensitivity of cancer cells to cisplatin $(85,86)$. Alternatively, LXR agonists and fluvastatin can reverse the effect of ox-LDL, suggesting LXR ligands and statins may be effective in the treatment of ovarian cancer (60). While the data remain limited, available evidence suggests that abnormal lipoprotein profiles might promote ovarian cancer development.

\section{LDL and ox-LDL in Gastric Cancer}

Gastric cancer is the second most common cancer worldwide and the third leading cause of cancer-related deaths (121). A prospective study reveals that higher LDL-C to be a risk factor for gastric cancer, and compared with healthy controls, serum LDL$\mathrm{C}$ levels were lower in patients with gastric cancer; whereas, LDL$\mathrm{C}$ levels in gastric cancer tissues are higher than normal tissues (170). More importantly, increased LDL levels favor cancer metastasis to lymph nodes (171). It is possible that diagnosed cancer at its late stage may cause a reduction in serum LDL-C levels due to a rapid cell division. Alternatively, through the LDLlowering effect, recent studies have demonstrated that statins reduce the risk of gastric cancer by inhibiting cancer cell growth and cell death (172). Despite multiple researches supporting the prognostic value of serum lipid levels in gastric cancer, a solid association has not been confirmed $(170,173)$.

Recent studies showed that the blood levels of ox-LDL increased in gastric cancer patients, and LOX-1 was up- regulated in gastric cancer tissues $(21,174)$. High expression of LOX-1 is not only related to cancer invasion and lymph node metastasis but is also associated with TNM stage and OS reduction (174). In vivo and in vitro experiments demonstrated that ox-LDL could activate the NF- $\kappa B$ signaling pathway via LOX-1, with subsequent upregulation of VEGF-C and promotion of the lymphatic metastasis of gastric cancer (21). Besides, LOX-1 promotes cell migration and invasion by activating the PI3K/ Akt/GSK3 $\beta$ pathway and then enhances the EMT process of gastric cancer cells (174). These results suggest that LOX-1 may represent a promising prognosis factor for gastric cancer and serves as a novel molecular target for gastric cancer therapies.

LDL and ox-LDL levels and their possible effects on the development of those types of cancers are summarized in Tables 1, 2 below, and different roles of LDL and ox-LDL in cancer progression summarized in Table 3.

\section{TARGETING LDL AND OX-LDL FOR CANCER THERAPY}

Given the association between high cholesterol levels and cancer progression, treatments aiming to lower serum cholesterol levels may have beneficial effects on cancer. Considering the role of LDL/ox-LDL in cancer occurrence, progression, and metastasis, targeting the receptors of LDL and ox-LDL may be a clinically valuable therapeutic strategy. It has been shown that the inhibition of LDLR activity in pancreatic and breast cancer cells can significantly reduce cholesterol absorption and subsequent inhibition of cell proliferation $(84,115)$. Many malignant cancers have an increased demand for lipoprotein due to the requirement for lipids for the rapid proliferation of the tumors, which is met by the increased availability of LDL through upregulation of LDLR. LDLR is not downregulated, especially in prostatic cancer with the elevation of LDL level in the body (44). Thereby, taking LDL as a carrier, anticancer drugs can target tumor cells more precisely and effectively. Other studies have shown that targeting ox-LDL-related receptors has the potential to reduce metastasis in a variety of in situ cancer models. In xenograft models, the inhibitory effect of LOX-1 significantly inhibits the formation of metastasis in tumorbearing mice (107). Thus, LDL and ox-LDL and their receptors play an essential role in the process of cancer treatment and can be used as an effective adjunct to current cancer treatment.

Traditional cholesterol-lowering drugs such as statins competitively inhibit the endogenous cholesterol synthesis by targeting the rate-limiting enzyme HMG-CoA reductase and block hydroxymethyl, to control the biosynthesis of cholesterol in the cell, which can effectively reduce LDL-C (178-180). In recent years, statins have been considered anti-cancer drugs (181). Statins are associated with significantly reduced risk of breast cancer, colorectal cancer, ovarian cancer, pancreatic cancer, lung cancer, and lymphoma, Statins have been shown to inhibit tumor growth at clinically relevant doses and diminish metastasis in animal models $(182,183)$. Besides, statins reduce mortality and the risk of prostate-specific antigen (PSA) recurrence in a dose-dependent manner after prostatectomy 
TABLE 1 | LDL levels and their possible effects on the development of selected types of cancer.

\begin{tabular}{|c|c|c|c|c|c|}
\hline Cancers & Study design & Experimental subjects & $\begin{array}{l}\text { LDL } \\
\text { level }\end{array}$ & Main effects & Ref \\
\hline \multirow[t]{4}{*}{ Breast cancer } & $\begin{array}{l}\text { Mendelian } \\
\text { randomization }\end{array}$ & $>400,000$ cases & $\uparrow$ & Increase cancer risk & $(75)$ \\
\hline & Prospective & 244 cases & $\uparrow$ & $\begin{array}{l}\text { Promote tumor growth and } \\
\text { differentiation }\end{array}$ & $(74)$ \\
\hline & In vitro & $\begin{array}{l}\text { HTB20, } 4 \text { T1, HTB126, MDA MB 231, MCF7, HS578T, MDA MB } \\
468 \text { cell lines }\end{array}$ & & $\begin{array}{l}\text { Promote proliferation, migration, } \\
\text { invasion, angiogenesis }\end{array}$ & $(48,83)$ \\
\hline & In vivo & 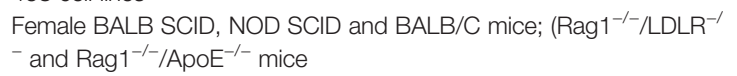 & $\uparrow$ & Promote tumor growth & $(84)$ \\
\hline \multirow[t]{4}{*}{ Colorectal cancer } & Case-cohort & 34148 cases & $\uparrow$ & Increase cancer risk & (96) \\
\hline & Retrospective & 453 cases & $\uparrow$ & Promote distant metastasis & (98) \\
\hline & In vitro & SW480, LoVo and RKO cell lines & & Promote migration & $(55)$ \\
\hline & In vivo & AOM/DSS-treated mice & $\uparrow$ & Enhance intestinal inflammation & (55) \\
\hline \multirow{3}{*}{$\begin{array}{l}\text { Pancreatic } \\
\text { cancer }\end{array}$} & Mendelian & 8769 cases & $\uparrow$ & Increase cancer risk & $(175)$ \\
\hline & In vitro & PK4A cell line & & Promote proliferation & $(115)$ \\
\hline & In vivo & Male Pdx1-Cre, Ink4a/Arf ${ }^{f / / f l}$ and LSL-Kras ${ }^{G 12 D}$ mice & $\uparrow$ & $\begin{array}{l}\text { Increase recurrence risk and drug } \\
\text { resistance }\end{array}$ & $(115)$ \\
\hline \multirow[t]{4}{*}{ Prostate cancer } & Cohort & 2842 cases & $\uparrow$ & Increase cancer risk & $(176)$ \\
\hline & Cross-sectional & 190 cases & $\uparrow$ & Increase cancer risk & $(127)$ \\
\hline & In vitro & LNCaP and VCaP cell lines & & Promote proliferation and migration & (129) \\
\hline & In vivo & C57BI/6J mice & $\uparrow$ & Promote tumor growth & $(131)$ \\
\hline \multirow[t]{4}{*}{ Renal cancer } & Retrospective & 362 cases & $\uparrow$ & Increase cancer risk & (139) \\
\hline & Case-control & Cancer patients:550 cases Control:570 cases & $\uparrow$ & Increase cancer risk & $(138)$ \\
\hline & In vitro & SK-45 and PNX0010 cell lines & & Resist chemotherapy & $(50)$ \\
\hline & In vivo & Male C.B17/lcr-scid mice & $\uparrow$ & Promote tumor growth & $(50)$ \\
\hline \multirow{4}{*}{$\begin{array}{l}\text { Hepatocellular } \\
\text { carcinoma }\end{array}$} & Prospective & 26891 cases & $\downarrow$ & Increase cancer risk & $(151)$ \\
\hline & Cohort & 16217 cases & $\downarrow$ & Increase mortality & $(152)$ \\
\hline & In vitro & HepG2 and Huh7 cell lines & & Promote inflammation & $(156)$ \\
\hline & In vitro & C57BL/6J mice & $\uparrow$ & Increase cancer risk & $(177)$ \\
\hline \multirow[t]{2}{*}{ Ovarian cancer } & Retrospective & 267 cases & $\uparrow$ & Improve 5-year RFS & $(168)$ \\
\hline & Case-control & Cancer patients: 22406 cases Controls: 40941 cases & & No significant associations & $(165)$ \\
\hline \multirow[t]{2}{*}{ Gastric cancer } & Case-control & Cancer patients: 412 cases Controls: 2934 cases & $\uparrow$ & Increase cancer risk & $(170)$ \\
\hline & Cross-sectional & 205 cases & $\uparrow$ & Predict metastasis risk & $(171)$ \\
\hline
\end{tabular}

$\uparrow$ : up-regulation, $\downarrow$ : down-regulation.

TABLE 2 | LDL levels and their possible effects on the development of selected types of cancer.

\begin{tabular}{|c|c|c|c|c|c|}
\hline Cancers & Study design & Experimental subjects & ox-LDL level & Main effects & Ref \\
\hline \multirow[t]{2}{*}{ Breast cancer } & Case-control & Cancer patients:32 cases Controls: 30 cases & $\uparrow$ & Increase cancer risk & (86) \\
\hline & In vitro & MCF10A cell line & & Promote tumorigenesis & $(88)$ \\
\hline \multirow[t]{3}{*}{ Colorectal cancer } & Case-control & $\begin{array}{l}\text { Cancer patients: } 161 \text { cases Controls: } 395 \\
\text { cases }\end{array}$ & $\uparrow$ & Increase cancer risk & $(102)$ \\
\hline & Retrospective & 52 cases & $\uparrow$ & Increase cancer risk & \\
\hline & & & & & $(103)$ \\
\hline Pancreatic cancer & In vitro & KLM-1 cell line & & Promote tumorigenesis and proliferation & (118) \\
\hline \multirow[t]{3}{*}{ Prostate cancer } & Retrospective & 75 cases & $\uparrow$ & $\begin{array}{l}\text { Promote Gleason score and lymph node } \\
\text { metastasis }\end{array}$ & $(135)$ \\
\hline & In vitro & LNCaP, PC-3, C4-2, C4-2B and DU-145 & & Promote proliferation, migration, and invasion & $\begin{array}{r}(20 \\
135 \\
136)\end{array}$ \\
\hline & In vivo & Male BALB/c mice & $\uparrow$ & Enhance tumor angiogenesis & $(136)$ \\
\hline \multirow[t]{2}{*}{$\begin{array}{l}\text { Hepatocellular } \\
\text { carcinoma }\end{array}$} & $\begin{array}{l}\text { Cross- } \\
\text { sectional }\end{array}$ & 50 cases & $\uparrow$ & Induce carcinogenesis & $(161)$ \\
\hline & In vivo & Female athymic nude mice and C57BL/6 mice & & Promote tumorigenesis & $(162)$ \\
\hline \multirow[t]{2}{*}{ Ovarian cancer } & Case-control & Cancer patients:32 cases Controls:30 cases & $\uparrow$ & Predict cancer risk & $(86)$ \\
\hline & In vitro & CAOV3, SKOV3 cell lines & & Promote proliferation and drug resistance & (86) \\
\hline \multirow[t]{3}{*}{ Gastric cancer } & Retrospective & 17 cases & $\uparrow$ & Promote lymph node metastasis & $(21)$ \\
\hline & In vitro & HGC-27 and MGC-803 cell lines & & Promote metastasis & $(21)$ \\
\hline & In vivo & Female BALB/c nude mice & $\uparrow$ & Promote lymph node metastasis & $(21)$ \\
\hline
\end{tabular}

$\uparrow:$ up-regulation, $\downarrow d o w n-r e g u l a t i o n$. 
TABLE 3 | Summary of the role of LDL and ox- LDL in cancer progression.

\begin{tabular}{|c|c|c|c|c|}
\hline Lipoproteins & Receptors & Mechanism & Effects on cancer & Ref \\
\hline \multirow[t]{4}{*}{ LDL } & LDLR & Inhibit PD1/L1 and $\gamma \delta$ T cells & Anti-tumor therapy resistance & $(51,53)$ \\
\hline & & Up-regulate Stemness genes & Enhance cell stemness & (55) \\
\hline & & $\begin{array}{l}\text { Activate Akt/ERK2, p38/MAPK, PI3K/Akt/mTOR signaling pathways; decrease } \\
\text { adhesion molecules expression }\end{array}$ & Proliferation and metastasis & $(48,50,55,82)$ \\
\hline & & Activate STAT3 signaling & Invasion & (49) \\
\hline \multirow[t]{4}{*}{ ox-LDL } & LOX-1, & Induce DNA damage by ROS, activate miR-210 expression & Inflammation and mutagenesis & $(39,57,58)$ \\
\hline & CD36 & Activate POX to up-regulated beclin-1 activate miR-155 & Autophagy & $(63,64)$ \\
\hline & & $\begin{array}{l}\text { Activate NF- } \mathrm{NB} \text { target genes VEGF, MMP-2, MMP-9 by binding with LOX-1; up- } \\
\text { regulate cytokines CT-1 by accumulating ox-LDL oxysterol metabolite }\end{array}$ & $\begin{array}{l}\text { Proliferation, invasion, and } \\
\text { angiogenesis }\end{array}$ & $(39,60)$ \\
\hline & & Activate PI3K/Akt/GSK3 $\beta$ signaling pathway & EMT and migration & $(174)$ \\
\hline
\end{tabular}

(184), as well as improve OS in patients with metastatic renal cancer (25.6 months vs. 18.9 months) (185).

Mevalonic acid, a the precursor of non-steroidal isoprenoids, is a lipid attachment molecule for small $G$ proteins, such as Ras, Rho, and Rac, and has been implicated in various aspects of tumor development and progression (179). Statins have been shown to inhibit the proliferation of breast cancer cells by suppressing FPP and GGPP modifications and activation of Ras, Rac, and Rho, small GTPases. In addition, statins inhibit cancer cell growth by inducing apoptosis through activation of Bax and down-regulation of the levels of anti-apoptotic protein Bcl-2 (186). However, the effects of statins on angiogenesis are divergent. Statins induce angiogenesis at low doses, while an opposite effect is observed at higher doses (187). Furthermore, statins can inhibit the viability and proliferation of cancer cells by blocking various signaling pathways, such as PI3K/ATK and MAPK, and may improve the efficiency of chemotherapy when used in combination with other chemotherapeutic agents (184). However, statins with different solubility show different effects on cancer therapy. Lipophilic statins have better anticancer activities than hydrophilic statins; this may be partly attributed to their better ability in diffusing into extrahepatic tumors. In this regard, it is proposed that hydrophilic statins are not effective in inhibiting extrahepatic HMG-CoA reductase, and are thus ineffective in reducing cancer susceptibility (188).

\section{CONCLUSION AND PROSPECTS}

Most cancers show a high demand for cholesterol, LDL or oxLDL to maintain rapid growth and survival. LDL and ox-LDL play divergent roles in different types of cancers. In certain types of cancer at their early stages, elevated plasma LDL-C levels in patients are observed, such as in colorectal cancer patients. However, plasma LDL-C was reported to be lowered in patients with metastatic cancer. The relationship between low plasma LDL-C levels and cancer can be explained by increased uptake of cholesterol from plasma by malignant cells to meet their own proliferation needs. Elevated plasma levels of either LDL or ox-LDL are positively correlated with the progression of breast cancer, colorectal cancer, and pancreatic cancer, but no such correlation has been found between ox-LDL and thyroid or nasopharyngeal cancers, which may be due to the differing needs for cholesterol in different cancer types. LDLR and LOX-1, as receptors for LDL and ox-LDL, respectively, are overexpressed in a variety of cancers and are associated with accelerated cancer progression. However, there is currently limited data on whether high expression levels of these receptors will be present increase the risk of cancer. The connection seems clear, and it is necessary to determine the correlation between LDL and ox-LDL-related receptors and cancer risk. Statins have multiple anti-cancer effects such as inhibition of cancer cell proliferation, promotion of cancer cell apoptosis, and enhancement of the efficacy of chemotherapy drugs, and liposoluble statins may be more suitable for cancer treatment.

Epidemiological studies have shown that cancer is often accompanied with metabolic diseases, such as hypertension, hyperlipidemia, and diabetes. Cancer patients often have highrisk habits such as smoking, drinking, and a high-fat diet. Such confounders may lead to elevated LDL/ox-LDL levels in cancer patients. Identifying the causes of elevated LDL and/or ox-LDL levels may help to elucidate novel therapies for reducing LDL and/ or ox-LDL levels in cancer patients. Complex feedback loops regulate cholesterol homeostasis, by only inhibiting one pathway of cholesterol metabolism might have little effect on tumor growth. With the increased discovery of inhibitors targeting cholesterol metabolism, the effects of combination therapy simultaneously block cholesterol synthesis, uptake, esterification, or cancer trafficking should be further explored. Despite exciting progress in this field, many fundamental questions remain to be addressed, such as could some drugs currently used for the treatment of metabolic diseases be repurposed as anti-tumor drugs? What is the most effective combination way to treat a particular type of cancer cells with different approaches? These unresolved issues reflect the urgent need for more research on the mechanism of cholesterol metabolism in cancer.

Taken together, these studies strongly suggest that LDL, oxLDL, as well as their receptors, play important roles in tumorigenesis and cancer development. Lowering LDL and oxLDL levels may be a novel therapeutic strategy to prevent cancer progression.

\section{AUTHOR CONTRIBUTIONS}

All authors contributed to the development of this review article. Critical analysis and review of the literature were performed by $\mathrm{C}-\mathrm{FD}$. The manuscript was written by $\mathrm{C}-\mathrm{FD}$ and $\mathrm{NZ}$ with revisions provided by T-JZ, H-FL, JG, D-FL, LQ. 


\section{FUNDING}

This work was supported by the National Natural Sciences Foundation of China (81973668, 81774130); the National Science Fund of Hunan Province for Distinguished Young

\section{REFERENCES}

1. Lyu J, Yang EJ, Shim JS. Cholesterol Trafficking: An Emerging Therapeutic Target for Angiogenesis and Cancer. Cells (2019) 8(5):389. doi: 10.3390/ cells8050389

2. Murai T. Cholesterol Lowering: Role in Cancer Prevention and Treatment. Biol Chem (2015) 396(1):1-11. doi: 10.1515/hsz-2014-0194

3. Allott EH, Howard LE, Cooperberg MR, Kane CJ, Aronson WJ, Terris MK, et al. Serum Lipid Profile and Risk of Prostate Cancer Recurrence: Results From the SEARCH Database. Cancer Epidemiol Biomarkers Prev (2014) 23 (11):2349-56. doi: 10.1158/1055-9965.EPI-14-0458

4. Huang B, Song BL, Xu C. Cholesterol Metabolism in Cancer: Mechanisms and Therapeutic Opportunities. Nat Metab (2020) 2(2):132-41. doi: 10.1038/s42255-020-0174-0

5. Beckwitt CH, Brufsky A, Oltvai ZN, Wells A. Statin Drugs to Reduce Breast Cancer Recurrence and Mortality. Breast Cancer Res: BCR (2018) 20(1):144. doi: 10.1186/s13058-018-1066-Z

6. Akinwunmi B, Vitonis AF, Titus L, Terry KL, Cramer DW. Statin Therapy and Association With Ovarian Cancer Risk in the New England Case Control (NEC) Study. Int J Cancer (2019) 144(5):991-1000. doi: 10.1002/ ijc. 31758

7. Zhou M, Zheng J, Bi J, Wu X, Lyu J, Gao K. Synergistic Inhibition of Colon Cancer Cell Growth by a Combination of Atorvastatin and Phloretin. Oncol Lett (2018) 15(2):1985-92. doi: 10.3892/ol.2017.7480

8. Nielsen SF, Nordestgaard BG, Bojesen SE. Statin Use and Reduced CancerRelated Mortality. New Engl J Med (2012) 367(19):1792-802. doi: 10.1056/ NEJMoa1201735

9. Xu H, Zhou S, Tang Q, Xia H, Bi F. Cholesterol Metabolism: New Functions and Therapeutic Approaches in Cancer. Biochim Biophys Acta Rev Cancer (2020) 1874(1):188394. doi: 10.1016/j.bbcan.2020.188394

10. Nazih H, Bard JM. Cholesterol, Oxysterols and LXRs in Breast Cancer Pathophysiology. Int J Mol Sci (2020) 21(4):1356. doi: 10.3390/ ijms21041356

11. Inoue M, Niki M, Ozeki Y, Nagi S, Chadeka EA, Yamaguchi T, et al. HighDensity Lipoprotein Suppresses Tumor Necrosis Factor Alpha Production by Mycobacteria-Infected Human Macrophages. Sci Rep (2018) 8(1):6736. doi: 10.1038/s41598-018-24233-1

12. Guo D, Bell EH, Mischel P, Chakravarti A. Targeting SREBP-1-Driven Lipid Metabolism to Treat Cancer. Curr Pharm Des (2014) 20(15):2619-26. doi: 10.2174/13816128113199990486

13. Hirsch HA, Iliopoulos D, Joshi A, Zhang Y, Jaeger SA, Bulyk M, et al. A Transcriptional Signature and Common Gene Networks Link Cancer With Lipid Metabolism and Diverse Human Diseases. Cancer Cell (2010) 17 (4):348-61. doi: 10.1016/j.ccr.2010.01.022

14. Damiano MG, Mutharasan RK, Tripathy S, McMahon KM, Thaxton CS. Templated High Density Lipoprotein Nanoparticles as Potential Therapies and for Molecular Delivery. Adv Drug Deliv Rev (2013) 65(5):649-62. doi: 10.1016/j.addr.2012.07.013

15. Kimbung S, Lettiero B, Feldt M, Bosch A, Borgquist S. High Expression of Cholesterol Biosynthesis Genes is Associated With Resistance to Statin Treatment and Inferior Survival in Breast Cancer. Oncotarget (2016) 7 (37):59640-51. doi: 10.18632/oncotarget.10746

16. Siemianowicz K, Gminski J, Stajszczyk M, Wojakowski W, Goss M, Machalski M, et al. Serum LDL Cholesterol Concentration and Lipoprotein Electrophoresis Pattern in Patients With Small Cell Lung Cancer. Int J Mol Med (2000) 5(1):55-7. doi: 10.3892/ijmm.5.1.55

17. Sottero B, Gargiulo S, Russo I, Barale C, Poli G, Cavalot F. Postprandial Dysmetabolism and Oxidative Stress in Type 2 Diabetes: Pathogenetic
Scholars (2018JJ1018); the Key Project of the Educational Department of Hunan Province (20A375); the Scientific Research Project of Changsha Science and Technology Bureau (No. kq2004060) and the First-Class Discipline of Pharmaceutical Science of Hunan.
Mechanisms and Therapeutic Strategies. Med Res Rev (2015) 35(5):9681031. doi: $10.1002 /$ med.21349

18. Negre-Salvayre A, Coatrieux C, Ingueneau C, Salvayre R. Advanced Lipid Peroxidation End Products in Oxidative Damage to Proteins. Potential Role in Diseases and Therapeutic Prospects for the Inhibitors. Br J Pharmacol (2008) 153(1):6-20. doi: 10.1038/sj.bjp.0707395

19. Balzan S, Lubrano V. LOX-1 Receptor: A Potential Link in Atherosclerosis and Cancer. Life Sci (2018) 198:79-86. doi: 10.1016/j.lfs.2018.02.024

20. González-Chavarría I, Fernandez E, Gutierrez N, González-Horta EE, Sandoval F, Cifuentes P, et al. LOX-1 Activation by oxLDL Triggers an Epithelial Mesenchymal Transition and Promotes Tumorigenic Potential in Prostate Cancer Cells. Cancer Lett (2018) 414:34-43. doi: 10.1016/ j.canlet.2017.10.035

21. Ma C, Xie J, Luo C, Yin H, Li R, Wang X, et al. OxLDL Promotes Lymphangiogenesis and Lymphatic Metastasis in Gastric Cancer by Upregulating VEGF-C Expression and Secretion. Int J Oncol (2019) 54 (2):572-84. doi: 10.3892/ijo.2018.4648

22. Swinnen JV, Brusselmans K, Verhoeven G. Increased Lipogenesis in Cancer Cells: New Players, Novel Targets. Curr Opin Clin Nutr Metab Care (2006) 9 (4):358-65. doi: 10.1097/01.mco.0000232894.28674.30

23. Chakraborty S, Cai Y, Tarr MA. In Vitro Oxidative Footprinting Provides Insight Into Apolipoprotein B-100 Structure in Low-Density Lipoprotein. Proteomics (2014) 14(21-22):2614-22. doi: 10.1002/pmic.201300174

24. Loregger A, Nelson JK, Zelcer N. Assaying Low-Density-Lipoprotein (LDL) Uptake Into Cells. Methods Mol Biol (Clifton NJ) (2017) 1583:53-63. doi: 10.1007/978-1-4939-6875-6_5

25. Jeon TI, Osborne TF. miRNA and Cholesterol Homeostasis. Biochim Biophys Acta (2016) 1861(12 Pt B):2041-6. doi: 10.1016/j.bbalip.2016.01.005

26. Peng C, Lei P, Li X, Xie H, Yang X, Zhang T, et al. Down-Regulated of SREBP-1 in Circulating Leukocyte is a Risk Factor for Atherosclerosis: A Case Control Study. Lipids Health Dis (2019) 18(1):177. doi: 10.1186/ s12944-019-1125-1

27. Afonso MS, Machado RM, Lavrador MS, Quintao ECR, Moore KJ, Lottenberg AM. Molecular Pathways Underlying Cholesterol Homeostasis. Nutrients (2018) 10(6):760. doi: 10.3390/nu10060760

28. Madison BB. Srebp2: A Master Regulator of Sterol and Fatty Acid Synthesis. J Lipid Res (2016) 57(3):333-5. doi: 10.1194/jlr.C066712

29. Lagace TA. PCSK9 and LDLR Degradation: Regulatory Mechanisms in Circulation and in Cells. Curr Opin Lipidol (2014) 25(5):387-93. doi: 10.1097/MOL.0000000000000114

30. Seidah NG. The PCSK9 Revolution and the Potential of PCSK9-Based Therapies to Reduce LDL-Cholesterol. Global Cardiol Sci Pract (2017) 2017(1):e201702. doi: 10.21542/gcsp.2017.2

31. Huang M, Zhao Z, Cao Q, You X, Wei S, Zhao J, et al. PAQR3 Modulates Blood Cholesterol Level by Facilitating Interaction Between LDLR and PCSK9. Metab: Clin Exp (2019) 94:88-95. doi: 10.1016/j.metabol. 2019.02.005

32. Wang Y, Liu ZP. PCSK9 Inhibitors: Novel Therapeutic Strategies for Lowering LDLCholesterol. Mini Rev Med Chem (2019) 19(2):165-76. doi: $10.2174 / 1389557518666180423111442$

33. Attie AD. ABCA1: At the Nexus of Cholesterol, HDL and Atherosclerosis. Trends Biochem Sci (2007) 32(4):172-9. doi: 10.1016/j.tibs.2007.02.001

34. Zelcer N, Hong C, Boyadjian R, Tontonoz P. LXR Regulates Cholesterol Uptake Through Idol-Dependent Ubiquitination of the LDL Receptor. Sci (New York NY) (2009) 325(5936):100-4. doi: 10.1126/science.1168974

35. Chade AR, Lerman A, Lerman LO. Kidney in Early Atherosclerosis. Hypertens (Dallas Tex: 1979) (2005) 45(6):1042-9. doi: 10.1161/ 01.HYP.0000167121.14254.a0 
36. Morita SY. Metabolism and Modification of Apolipoprotein B-Containing Lipoproteins Involved in Dyslipidemia and Atherosclerosis. Biol Pharm Bull (2016) 39(1):1-24. doi: 10.1248/bpb.b15-00716

37. Sukhbold E, Sekimoto S, Watanabe E, Yamazaki A, Yang L, Takasugi M, et al. Effects of Oolonghomobisflavan A on Oxidation of Low-Density Lipoprotein. Biosci Biotechnol Biochem (2017) 81(8):1569-75. doi: 10.1080/09168451.2017.1314758

38. Zhang X, Han X, Zhang P, Zhou T, Chen Y, Jin J, et al. Morin Attenuates Oxidized Low-Density Lipoprotein-Mediated Injury by Inducing Autophagy via Activating AMPK Signalling in HUVECs. Clin Exp Pharmacol Physiol (2019) 46(11):1053-60. doi: 10.1111/1440-1681.13160

39. Bitorina AV, Oligschlaeger Y, Shiri-Sverdlov R, Theys J. Low Profile High Value Target: The Role of OxLDL in Cancer. Biochim Biophys Acta Mol Cell Biol Lipids (2019) 1864(12):158518. doi: 10.1016/j.bbalip.2019.158518

40. Mehta N, Hordines J, Volpe C, Doerr R, Cohen SA. Cellular Effects of Hypercholesterolemia in Modulation of Cancer Growth and Metastasis: A Review of the Evidence. Surg Oncol (1997) 6(3):179-85. doi: 10.1016/S09607404(97)00027-3

41. Kuzu OF, Noory MA, Robertson GP. The Role of Cholesterol in Cancer. Cancer Res (2016) 76(8):2063-70. doi: 10.1158/0008-5472.CAN-15-2613

42. Llaverias G, Danilo C, Mercier I, Daumer K, Capozza F, Williams TM, et al. Role of Cholesterol in the Development and Progression of Breast Cancer. Am J Pathol (2011) 178(1):402-12. doi: 10.1016/j.ajpath.2010.11.005

43. Drabkin HA, Gemmill RM. Cholesterol and the Development of Clear-Cell Renal Carcinoma. Curr Opin Pharmacol (2012) 12(6):742-50. doi: 10.1016/ j.coph.2012.08.002

44. Chen Y, Hughes-Fulford M. Human Prostate Cancer Cells Lack Feedback Regulation of Low-Density Lipoprotein Receptor and Its Regulator, SREBP2. Int J Cancer (2001) 91(1):41-5. doi: 10.1002/1097-0215(20010101)91:1<41:: AID-IJC1009>3.0.CO;2-2

45. Du B, Shim JS. Targeting Epithelial-Mesenchymal Transition (EMT) to Overcome Drug Resistance in Cancer. Molecules (Basel Switzerland) (2016) 21(7):965. doi: 10.3390/molecules21070965

46. Xu W, Yang Z, Lu N. A New Role for the PI3K/Akt Signaling Pathway in the Epithelial-Mesenchymal Transition. Cell Adhesion Migration (2015) 9 (4):317-24. doi: 10.1080/19336918.2015.1016686

47. Yang J, Nie J, Ma X, Wei Y, Peng Y, Wei X. Targeting PI3K in Cancer: Mechanisms and Advances in Clinical Trials. Mol Cancer (2019) 18(1):26. doi: 10.1186/s12943-019-0954-x

48. dos Santos CR, Domingues G, Matias I, Matos J, Fonseca I, de Almeida JM, et al. LDL-Cholesterol Signaling Induces Breast Cancer Proliferation and Invasion. Lipids Health Dis (2014) 13:16. doi: 10.1186/1476-511X-13-16

49. Jung YY, Ko JH, Um JY, Chinnathambi A, Alharbi SA, Sethi G, et al. LDL Cholesterol Promotes the Proliferation of Prostate and Pancreatic Cancer Cells by Activating the STAT3 Pathway. J Cell Physiol (2021) 236(7):525364. doi: $10.1002 /$ jcp.30229

50. Naito S, Makhov P, Astsaturov I, Golovine K, Tulin A, Kutikov A, et al. LDL Cholesterol Counteracts the Antitumour Effect of Tyrosine Kinase Inhibitors Against Renal Cell Carcinoma. Br J Cancer (2017) 116(9):1203-7. doi: 10.1038/bjc. 2017.77

51. Rodrigues NV, Correia DV, Mensurado S, Nóbrega-Pereira S, deBarros A, Kyle-Cezar F, et al. Low-Density Lipoprotein Uptake Inhibits the Activation and Antitumor Functions of Human V $\gamma 9 \mathrm{v} \delta 2 \mathrm{~T}$ Cells. Cancer Immunol Res (2018) 6(4):448-57. doi: 10.1158/2326-6066.CIR-17-0327

52. McCaw L, Shi Y, Wang G, Li YJ, Spaner DE. Low Density Lipoproteins Amplify Cytokine-Signaling in Chronic Lymphocytic Leukemia Cells. EBioMedicine (2017) 15:24-35. doi: 10.1016/j.ebiom.2016.11.033

53. Khojandi N, Kuehm LM, Piening A, Donlin MJ, Hsueh EC, Schwartz TL, et al. Oxidized Lipoproteins Promote Resistance to Cancer Immunotherapy Independent of Patient Obesity. Cancer Immunol Res (2021) 9(2):214-26. doi: 10.1158/2326-6066.CIR-20-0358

54. Mehta N, Hordines J, Sykes D, Doerr RJ, Cohen SA. Low Density Lipoproteins and Lovastatin Modulate the Organ-Specific Transendothelial Migration of Primary and Metastatic Human Colon Adenocarcinoma Cell Lines In Vitro. Clin Exp Eetastasis (1998) 16 (7):587-94. doi: 10.1023/A:1006548902592

55. Wang C, Li P, Xuan J, Zhu C, Liu J, Shan L, et al. Cholesterol Enhances Colorectal Cancer Progression via ROS Elevation and MAPK Signaling
Pathway Activation. Cell Physiol Biochem (2017) 42(2):729-42. doi: 10.1159/ 000477890

56. Diakowska D, Grabowski K, Nienartowicz M, Zarębski P, Fudalej K, Markocka-Maczka K. Circulating Oxidized Low-Density Lipoproteins and Antibodies Ágainst Oxidized Low-Density Lipoproteins as Potential Biomarkers of Colorectal Cancer. Gastroenterol Res Pract (2015) 2015:146819. doi: 10.1155/2015/146819

57. Liu Y, Wang Y, Xu Q, Zhou X, Qin Z, Chen C, et al. Prognostic Evaluation of microRNA-210 in Various Carcinomas: Evidence From 19 Studies. Medicine (2017) 96(43):e8113. doi: 10.1097/MD.0000000000008113

58. Chen KC, Liao YC, Wang JY, Lin YC, Chen CH, Juo SH. Oxidized LowDensity Lipoprotein is a Common Risk Factor for Cardiovascular Diseases and Gastroenterological Cancers via Epigenomical Regulation of microRNA210. Oncotarget (2015) 6(27):24105-18. doi: 10.18632/oncotarget.4152

59. Hale JS, Otvos B, Sinyuk M, Alvarado AG, Hitomi M, Stoltz K, et al. Cancer Stem Cell-Specific Scavenger Receptor CD36 Drives Glioblastoma Progression. Stem Cells (Dayton Ohio) (2014) 32(7):1746-58. doi: 10.1002/stem.1716

60. Scoles DR, Xu X, Wang H, Tran H, Taylor-Harding B, Li A, et al. Liver X Receptor Agonist Inhibits Proliferation of Ovarian Carcinoma Cells Stimulated by Oxidized Low Density Lipoprotein. Gynecol Oncol (2010) 116(1):109-16. doi: 10.1016/j.ygyno.2009.09.034

61. Amaravadi RK, Lippincott-Schwartz J, Yin XM, Weiss WA, Takebe N, Timmer W, et al. Principles and Current Strategies for Targeting Autophagy for Cancer Treatment. Clin Cancer Res (2011) 17(4):654-66. doi: 10.1158/ 1078-0432.CCR-10-2634

62. Ferro F, Servais S, Besson P, Roger S, Dumas JF, Brisson L. Autophagy and Mitophagy in Cancer Metabolic Remodelling. Semin Cell Dev Biol (2020) 98:129-38. doi: 10.1016/j.semcdb.2019.05.029

63. Zabirnyk O, Liu W, Khalil S, Sharma A, Phang JM. Oxidized Low-Density Lipoproteins Upregulate Proline Oxidase to Initiate ROS-Dependent Autophagy. Carcinogenesis (2010) 31(3):446-54. doi: 10.1093/carcin/bgp299

64. Zhang Z, Pan X, Yang S, Ma A, Wang K, Wang Y, et al. miR-155 Promotes Ox-LDL-Induced Autophagy in Human Umbilical Vein Endothelial Cells. Mediators Inflammation (2017) 2017:9174801. doi: 10.1155/2017/9174801

65. Gugnoni M, Sancisi V, Manzotti G, Gandolfi G, Ciarrocchi A. Autophagy and Epithelial-Mesenchymal Transition: An Intricate Interplay in Cancer. Cell Death Dis (2016) 7(12):e2520. doi: 10.1038/cddis.2016.415

66. Koonen DP, Jacobs RL, Febbraio M, Young ME, Soltys CL, Ong H, et al. Increased Hepatic CD36 Expression Contributes to Dyslipidemia Associated With Diet-Induced Obesity. Diabetes (2007) 56(12):2863-71. doi: 10.2337/ db07-0907

67. Chistiakov DA, Orekhov AN, Bobryshev YV. LOX-1-Mediated Effects on Vascular Cells in Atherosclerosis. Cell Physiol Biochem (2016) 38(5):1851-9. doi: 10.1159/000443123

68. Wang J, Li Y. CD36 Tango in Cancer: Signaling Pathways and Functions. Theranostics (2019) 9(17):4893-908. doi: 10.7150/thno.36037

69. Park YM, Drazba JA, Vasanji A, Egelhoff T, Febbraio M, Silverstein RL. Oxidized LDL/CD36 Interaction Induces Loss of Cell Polarity and Inhibits Macrophage Locomotion. Mol Biol Cell (2012) 23(16):3057-68. doi: 10.1091/mbc.e11-12-1051

70. Nath A, Li I, Roberts LR, Chan C. Elevated Free Fatty Acid Uptake via CD36 Promotes Epithelial-Mesenchymal Transition in Hepatocellular Carcinoma. Sci Rep (2015) 5:14752. doi: 10.1038/srep14752

71. Reiner AS, Sisti J, John EM, Lynch CF, Brooks JD, Mellemkjær L, et al. Breast Cancer Family History and Contralateral Breast Cancer Risk in Young Women: An Update From the Women's Environmental Cancer and Radiation Epidemiology Study. J Clin Oncol (2018) 36(15):1513-20. doi: 10.1200/JCO.2017.77.3424

72. Wu X, Zahari MS, Ma B, Liu R, Renuse S, Sahasrabuddhe NA, et al. Global Phosphotyrosine Survey in Triple-Negative Breast Cancer Reveals Activation of Multiple Tyrosine Kinase Signaling Pathways. Oncotarget (2015) 6(30):29143-60. doi: 10.18632/oncotarget.5020

73. Vuong D, Simpson PT, Green B, Cummings MC, Lakhani SR. Molecular Classification of Breast Cancer. Virchows Archiv (2014) 465(1):1-14. doi: 10.1007/s00428-014-1593-7

74. Rodrigues Dos Santos C, Fonseca I, Dias S, Mendes de Almeida JC. Plasma Level of LDL-Cholesterol at Diagnosis is a Predictor Factor of Breast Tumor Progression. BMC Cancer (2014) 14:132. doi: 10.1186/1471-2407-14-132 
75. Nowak C, Ärnlöv J. A Mendelian Randomization Study of the Effects of Blood Lipids on Breast Cancer Risk. Nat Commun (2018) 9(1):3957. doi: 10.1038/s41467-018-06467-9

76. Johnson KE, Siewert KM, Klarin D, Damrauer SM, Chang KM, Tsao PS, et al. The Relationship Between Circulating Lipids and Breast Cancer Risk: A Mendelian Randomization Study. PloS Med (2020) 17(9):e1003302. doi: 10.1371/journal.pmed.1003302

77. Martin LJ, Melnichouk O, Huszti E, Connelly PW, Greenberg CV, Minkin S, et al. Serum Lipids, Lipoproteins, and Risk of Breast Cancer: A Nested CaseControl Study Using Multiple Time Points. J Natl Cancer Inst (2015) 107(5): djv032. doi: 10.1093/jnci/djv032

78. Llanos AA, Makambi KH, Tucker CA, Wallington SF, Shields PG, AdamsCampbell LL. Cholesterol, Lipoproteins, and Breast Cancer Risk in African American Women. Ethnicity Dis (2012) 22(3):281-7.

79. Taylor AE, Davies NM, Ware JJ, VanderWeele T, Smith GD, Munafò MR. Mendelian Randomization in Health Research: Using Appropriate Genetic Variants and Avoiding Biased Estimates. Econ Hum Biol (2014) 13(100):99106. doi: 10.1016/j.ehb.2013.12.002

80. de Gonzalo-Calvo D, López-Vilaró L, Nasarre L, Perez-Olabarria M, Vázquez T, Escuin D, et al. Intratumor Cholesteryl Ester Accumulation Is Associated With Human Breast Cancer Proliferation and Aggressive Potential: A Molecular and Clinicopathological Study. BMC Cancer (2015) 15:460. doi: 10.1186/s12885-015-1469-5

81. Revilla G, Cedó L, Tondo M, Moral A, Pérez JI, Corcoy R, et al. LDL, HDL and Endocrine-Related Cancer: From Pathogenic Mechanisms to Therapies. Semin Cancer Biol (2021) 73:134-57. doi: 10.1016/j.semcancer.2020.11.012

82. Mebratu Y, Tesfaigzi Y. How ERK1/2 Activation Controls Cell Proliferation and Cell Death: Is Subcellular Localization the Answer? Cell Cycle (Georgetown Tex) (2009) 8(8):1168-75. doi: 10.4161/cc.8.8.8147

83. Lu CW, Lo YH, Chen CH, Lin CY, Tsai CH, Chen PJ, et al. But Not HDL, Promote Breast Cancer Cell Proliferation, Metastasis and Angiogenesis. Cancer Lett (2017) 388:130-8. doi: 10.1016/j.canlet.2016.11.033

84. Gallagher EJ, Zelenko Z, Neel BA, Antoniou IM, Rajan L, Kase N, et al. Elevated Tumor LDLR Expression Accelerates LDL Cholesterol-Mediated Breast Cancer Growth in Mouse Models of Hyperlipidemia. Oncogene (2017) 36(46):6462-71. doi: 10.1038/onc.2017.247

85. Cedó L, Reddy ST, Mato E, Blanco-Vaca F, Escolà-Gil JC. HDL and LDL: Potential New Players in Breast Cancer Development. J Clin Med (2019) 8 (6):853. doi: $10.3390 / \mathrm{jcm} 8060853$

86. Delimaris I, Faviou E, Antonakos G, Stathopoulou E, Zachari A, DionyssiouAsteriou A. Oxidized LDL, Serum Oxidizability and Serum Lipid Levels in Patients With Breast or Ovarian Cancer. Clin Biochem (2007) 40(15):112934. doi: 10.1016/j.clinbiochem.2007.06.007

87. Pucci S, Polidoro C, Greggi C, Amati F, Morini E, Murdocca M, et al. ProOncogenic Action of LOX-1 and its Splice Variant LOX-1 $\Delta 4$ in Breast Cancer Phenotypes. Cell Death Dis (2019) 10(2):53. doi: 10.1038/s41419018-1279-1

88. Khaidakov M, Mehta JL. Oxidized LDL Triggers Pro-Oncogenic Signaling in Human Breast Mammary Epithelial Cells Partly via Stimulation of MiR-21. PloS One (2012) 7(10):e46973. doi: 10.1371/ journal.pone.0046973

89. Wang B, Zhao H, Zhao L, Zhang Y, Wan Q, Shen Y, et al. Up-Regulation of OLR1 Expression by TBC1D3 Through Activation of Tnfo/NF- $\kappa b$ Pathway Promotes the Migration of Human Breast Cancer Cells. Cancer Lett (2017) 408:60-70. doi: 10.1016/j.canlet.2017.08.021

90. Liang M, Zhang P, Fu J. Up-Regulation of LOX-1 Expression by TNF-Alpha Promotes Trans-Endothelial Migration of MDA-MB-231 Breast Cancer Cells. Cancer Lett (2007) 258(1):31-7. doi: 10.1016/j.canlet.2007.08.003

91. Khaidakov M, Mitra S, Kang BY, Wang X, Kadlubar S, Novelli G, et al. Oxidized LDL Receptor 1 (OLR1) as a Possible Link Between Obesity, Dyslipidemia and Cancer. PloS One (2011) 6(5):e20277. doi: 10.1371/ journal.pone.0020277

92. Rizzacasa B, Morini E, Pucci S, Murdocca M, Novelli G, Amati F. LOX-1 and Its Splice Variants: A New Challenge for Atherosclerosis and CancerTargeted Therapies. Int J Mol Sci (2017) 18(2):290. doi: 10.3390/ ijms18020290

93. Bardou M, Barkun AN, Martel M. Obesity and Colorectal Cancer. Gut (2013) 62(6):933-47. doi: 10.1136/gutjnl-2013-304701
94. Park J, Morley TS, Kim M, Clegg DJ, Scherer PE. Obesity and CancerMechanisms Underlying Tumour Progression and Recurrence. Nat Rev Endocrinol (2014) 10(8):455-65. doi: 10.1038/nrendo.2014.94

95. Yang Y, Gao G, Shi J, Zhang J. Increased Blood Lipid Level is Associated With Cancer-Specific Mortality and All-Cause Mortality in Patients With Colorectal Cancer ( $\geq 65$ Years): A Population-Based Prospective Cohort Study. Risk Manage Healthc Policy (2020) 13:855-63. doi: 10.2147/ RMHP.S260113

96. Agnoli C, Grioni S, Sieri S, Sacerdote C, Vineis P, Tumino R, et al. Colorectal Cancer Risk and Dyslipidemia: A Case-Cohort Study Nested in an Italian Multicentre Cohort. Cancer Epidemiol (2014) 38(2):144-51. doi: 10.1016/ j.canep.2014.02.002

97. Zhang X, Zhao XW, Liu DB, Han CZ, Du LL, Jing JX, et al. Lipid Levels in Serum and Cancerous Tissues of Colorectal Cancer Patients. World J Gastroenterol (2014) 20(26):8646-52. doi: 10.3748/wjg.v20.i26.8646

98. Liao F, He W, Jiang C, Yin C, Guo G, Chen X, et al. A High LDL-C to HDLC Ratio Predicts Poor Prognosis for Initially Metastatic Colorectal Cancer Patients With Elevations in LDL-C. OncoTargets Ther (2015) 8:3135-42. doi: 10.2147/OTT.S90479

99. Notarnicola M, Altomare DF, Correale M, Ruggieri E, D’Attoma B, Mastrosimini A, et al. Serum Lipid Profile in Colorectal Cancer Patients With and Without Synchronous Distant Metastases. Oncology (2005) 68(46):371-4. doi: 10.1159/000086977

100. Sharma B, Gupta V, Dahiya D, Kumar H, Vaiphei K, Agnihotri N. Clinical Relevance of Cholesterol Homeostasis Genes in Colorectal Cancer. Biochim Biophys Acta Mol Cell Biol Lipids (2019) 1864(10):1314-27. doi: 10.1016/ j.bbalip.2019.06.008

101. LaRosa JC. Lipids and Cardiovascular Disease: Do the Findings and Therapy Apply Equally to Men and Women? Women's Health Issues (1992) 2(2):10211. discussion 11-3. doi: 10.1016/s1049-3867(05)80278-6

102. Suzuki K, Ito Y, Wakai K, Kawado M, Hashimoto S, Toyoshima H, et al. Serum Oxidized Low-Density Lipoprotein Levels and Risk of Colorectal Cancer: A Case-Control Study Nested in the Japan Collaborative Cohort Study. Cancer Epidemiol Biomarkers Prev (2004) 13(11 Pt 1):1781-7.

103. Keshk WA, Zineldeen DH, Wasfy RE, El-Khadrawy OH. Fatty Acid Synthase/Oxidized Low-Density Lipoprotein as Metabolic Oncogenes Linking Obesity to Colon Cancer via NF-Kappa B in Egyptians. Med Oncol (Northwood London England) (2014) 31(10):192. doi: 10.1007/ s12032-014-0192-4

104. Murdocca M, Mango R, Pucci S, Biocca S, Testa B, Capuano R, et al. The Lectin-Like Oxidized LDL Receptor-1: A New Potential Molecular Target in Colorectal Cancer. Oncotarget (2016) 7(12):14765-80. doi: 10.18632/ oncotarget.7430

105. Murdocca M, De Masi C, Pucci S, Mango R, Novelli G, Di Natale C, et al. LOX-1 and Cancer: An Indissoluble Liaison. Cancer Gene Ther (2021) 28(1011):1088-98. doi: 10.1038/s41417-020-00279-0

106. Nakashima-Nakasuga C, Hazama S, Suzuki N, Nakagami Y, Xu M, Yoshida S, et al. Serum LOX-1 is a Novel Prognostic Biomarker of Colorectal Cancer. Int J Clin Oncol (2020) 25(7):1308-17. doi: 10.1007/s10147-020-01673-2

107. Murdocca M, Capuano R, Pucci S, Cicconi R, Polidoro C, Catini A, et al. Targeting LOX-1 Inhibits Colorectal Cancer Metastasis in an Animal Model. Front Oncol (2019) 9:927. doi: 10.3389/fonc.2019.00927

108. Chen-Zhao X, Hernando O, López M, Sánchez E, Montero A, GarcíaAranda M, et al. A Prospective Observational Study of the Clinical and Pathological Impact of Stereotactic Body Radiotherapy (SBRT) as a Neoadjuvant Strategy of Chemoradiation in Pancreatic Cancer. Clin Trans Oncol (2020) 22(9):1499-505. doi: 10.1007/s12094-020-02287-w

109. Louvet C, Labianca R, Hammel P, Lledo G, Zampino MG, André T, et al. Gemcitabine in Combination With Oxaliplatin Compared With Gemcitabine Alone in Locally Advanced or Metastatic Pancreatic Cancer: Results of a GERCOR and GISCAD Phase III Trial. J Clin Oncol (2005) 23 (15):3509-16. doi: 10.1200/JCO.2005.06.023

110. Maisonneuve P, Lowenfels AB. Epidemiology of Pancreatic Cancer: An Update. Digestive Dis (Basel Switzerland) (2010) 28(4-5):645-56. doi: 10.1159/000320068

111. Aune D, Greenwood DC, Chan DS, Vieira R, Vieira AR, Navarro Rosenblatt DA, et al. Body Mass Index, Abdominal Fatness and Pancreatic Cancer Risk: A Systematic Review and non-Linear Dose-Response Meta-Analysis of 
Prospective Studies. Ann Oncol (2012) 23(4):843-52. doi: 10.1093/annonc/ mdr398

112. Lucenteforte E, La Vecchia C, Silverman D, Petersen GM, Bracci PM, Ji BT, et al. Alcohol Consumption and Pancreatic Cancer: A Pooled Analysis in the International Pancreatic Cancer Case-Control Consortium (Panc4). Ann Oncol (2012) 23(2):374-82. doi: 10.1093/annonc/mdr120

113. Stolzenberg-Solomon RZ, Pietinen P, Taylor PR, Virtamo J, Albanes D. A Prospective Study of Medical Conditions, Anthropometry, Physical Activity, and Pancreatic Cancer in Male Smokers (Finland). Cancer Causes Control (2002) 13(5):417-26. doi: 10.1023/A:1015729615148

114. Vasseur S, Guillaumond F. LDL Receptor: An Open Route to Feed Pancreatic Tumor Cells. Mol Cell Oncol (2016) 3(1):e1033586. doi: 10.1080/ 23723556.2015.1033586

115. Guillaumond F, Bidaut G, Ouaissi M, Servais S, Gouirand V, Olivares O, et al. Cholesterol Uptake Disruption, in Association With Chemotherapy, Is a Promising Combined Metabolic Therapy for Pancreatic Adenocarcinoma. Proc Natl Acad Sci USA (2015) 112(8):2473-8. doi: 10.1073/pnas.1421601112

116. Chen H, Qin S, Wang M, Zhang T, Zhang S. Association Between Cholesterol Intake and Pancreatic Cancer Risk: Evidence From a MetaAnalysis. Sci Rep (2015) 5:8243. doi: 10.1038/srep08243

117. Zhang J, Zhang L, Li C, Yang C, Li L, Song S, et al. LOX-1 is a Poor Prognostic Indicator and Induces Epithelial-Mesenchymal Transition and Metastasis in Pancreatic Cancer Patients. Cell Oncol (Dordrecht) (2018) 41 (1):73-84. doi: 10.1007/s13402-017-0360-6

118. Bitorina AV, Oligschlaeger Y, Ding L, Yadati T, Westheim A, Houben T, et al. OxLDL as an Inducer of a Metabolic Shift in Cancer Cells. J Cancer (2021) 12(19):5817-24. doi: 10.7150/jca.56307

119. Yang G, Xiong G, Feng M, Zhao F, Qiu J, Liu Y, et al. OLR1 Promotes Pancreatic Cancer Metastasis via Increased C-Myc Expression and Transcription of HMGA2. Mol Cancer Res (2020) 18(5):685-97. doi: 10.1158/1541-7786.MCR-19-0718

120. Xiong G, Liu C, Yang G, Feng M, Xu J, Zhao F, et al. Long Noncoding RNA GSTM3TV2 Upregulates LAT2 and OLR1 by Competitively Sponging Let-7 to Promote Gemcitabine Resistance in Pancreatic Cancer. J Hematol Oncol (2019) 12(1):97. doi: 10.1186/s13045-019-0777-7

121. Bray F, Ferlay J, Soerjomataram I, Siegel RL, Torre LA, Jemal A. Global Cancer Statistics 2018: GLOBOCAN Estimates of Incidence and Mortality Worldwide for 36 Cancers in 185 Countries. CA: Cancer J Clin (2018) 68 (6):394-424. doi: 10.3322/caac.21492

122. Pelton K, Freeman MR, Solomon KR. Cholesterol and Prostate Cancer. Curr Opin Pharmacol (2012) 12(6):751-9. doi: 10.1016/j.coph.2012.07.006

123. YuPeng L, YuXue Z, PengFei L, Cheng C, YaShuang Z, DaPeng L, et al. Cholesterol Levels in Blood and the Risk of Prostate Cancer: A MetaAnalysis of 14 Prospective Studies. Cancer Epidemiol Biomarkers Prev (2015) 24(7):1086-93. doi: 10.1158/1055-9965.EPI-14-1329

124. His M, Zelek L, Deschasaux M, Pouchieu C, Kesse-Guyot E, Hercberg S, et al. Prospective Associations Between Serum Biomarkers of Lipid Metabolism and Overall, Breast and Prostate Cancer Risk. Eur J Epidemiol (2014) 29 (2):119-32. doi: 10.1007/s10654-014-9884-5

125. Bull CJ, Bonilla C, Holly JM, Perks CM, Davies N, Haycock P, et al. Blood Lipids and Prostate Cancer: A Mendelian Randomization Analysis. Cancer Med (2016) 5(6):1125-36. doi: 10.1002/cam4.695

126. Magura L, Blanchard R, Hope B, Beal JR, Schwartz GG, Sahmoun AE. Hypercholesterolemia and Prostate Cancer: A Hospital-Based Case-Control Study. Cancer Causes Control (2008) 19(10):1259-66. doi: 10.1007/s10552008-9197-7

127. Tewari R, Chhabra M, Natu SM, Goel A, Dalela D, Goel MM, et al. Significant Association of Metabolic Indices, Lipid Profile, and Androgen Levels With Prostate Cancer. Asian Pac J Cancer Prevent: APJCP (2014) 15 (22):9841-6. doi: 10.7314/APJCP.2014.15.22.9841

128. Zhang JQ, Geng H, Ma M, Nan XY, Sheng BW. Metabolic Syndrome Components are Associated With Increased Prostate Cancer Risk. Med Sci Monit (2015) 21:2387-96. doi: 10.12659/MSM.893442

129. Murtola TJ, Syvälä H, Pennanen P, Bläuer M, Solakivi T, Ylikomi T, et al. The Importance of LDL and Cholesterol Metabolism for Prostate Epithelial Cell Growth. PloS One (2012) 7(6):e39445. doi: 10.1371/journal.pone.0039445

130. Yue S, Li J, Lee SY, Lee HJ, Shao T, Song B, et al. Cholesteryl Ester Accumulation Induced by PTEN Loss and PI3K/AKT Activation
Underlies Human Prostate Cancer Aggressiveness. Cell Metab (2014) 19 (3):393-406. doi: 10.1016/j.cmet.2014.01.019

131. Llaverias G, Danilo C, Wang Y, Witkiewicz AK, Daumer K, Lisanti MP, et al. A Western-Type Diet Accelerates Tumor Progression in an Autochthonous Mouse Model of Prostate Cancer. Am J Pathol (2010) 177(6):3180-91. doi: 10.2353/ajpath.2010.100568

132. Thysell E, Surowiec I, Hörnberg E, Crnalic S, Widmark A, Johansson AI, et al. Metabolomic Characterization of Human Prostate Cancer Bone Metastases Reveals Increased Levels of Cholesterol. PloS One (2010) 5(12): e14175. doi: 10.1371/journal.pone.0014175

133. Hughes-Fulford M, Chen Y, Tjandrawinata RR. Fatty Acid Regulates Gene Expression and Growth of Human Prostate Cancer PC-3 Cells. Carcinogenesis (2001) 22(5):701-7. doi: 10.1093/carcin/22.5.701

134. Sun P, Zhang N, Hua H, Liang Q, Zhang X, Sun Q, et al. Low Density Lipoprotein Peptide Conjugated Submicron Emulsions for Combating Prostate Cancer. Biomed Pharmacother = Biomed Pharmacother (2017) 86:612-9. doi: 10.1016/j.biopha.2016.11.103

135. Wan F, Qin X, Zhang G, Lu X, Zhu Y, Zhang H, et al. Oxidized Low-Density Lipoprotein Is Associated With Advanced-Stage Prostate Cancer. Tumour Biol (2015) 36(5):3573-82. doi: 10.1007/s13277-014-2994-6

136. González-Chavarría I, Cerro RP, Parra NP, Sandoval FA, Zuñiga FA, Omazábal VA, et al. Lectin-Like Oxidized LDL Receptor-1 is an Enhancer of Tumor Angiogenesis in Human Prostate Cancer Cells. PloS One (2014) 9 (8):e106219. doi: 10.1371/journal.pone.0106219

137. Wettersten HI, Aboud OA, Lara PN Jr, Weiss RH. Metabolic Reprogramming in Clear Cell Renal Cell Carcinoma. Nat Rev Nephrol (2017) 13(7):410-9. doi: 10.1038/nrneph.2017.59

138. Zhang GM, Zhu Y, Luo L, Zhang HL, Gu CY, Sun LJ, et al. Prevalence of Dyslipidaemia in Patients With Renal Cell Carcinoma: A Case-Control Study in China. BJU Int (2014) 113(5b):E75-81. doi: 10.1111/bju.12581

139. Zhang CJ, Zhu N, Wang YX, Liu LP, Zhao TJ, Wu HT, et al. Celastrol Attenuates Lipid Accumulation and Stemness of Clear Cell Renal Cell Carcinoma via CAV-1/LOX-1 Pathway. Front Pharmacol (2021) 12:658092. doi: 10.3389/fphar.2021.658092

140. Zhang C, Yu L, Xu T, Hao Y, Zhang X, Liu Z, et al. Association of Dyslipidemia With Renal Cell Carcinoma: A 1:2 Matched Case-Control Study. PloS One (2013) 8(3):e59796. doi: 10.1371/journal.pone.0059796

141. Wu G, Wang Q, Xu Y, Li J, Zhang H, Qi G, et al. Targeting the Transcription Factor Receptor LXR to Treat Clear Cell Renal Cell Carcinoma: Agonist or Inverse Agonist? Cell Death Dis (2019) 10 (6):416. doi: 10.1038/s41419-019-1654-6

142. Velagapudi S, Schraml P, Yalcinkaya M, Bolck HA, Rohrer L, Moch H, et al. Scavenger Receptor BI Promotes Cytoplasmic Accumulation of Lipoproteins in Clear-Cell Renal Cell Carcinoma. J Lipid Res (2018) 59(11):2188-201. doi: 10.1194/jlr.M083311

143. Murdocca M, Torino F, Pucci S, Costantini M, Capuano R, Greggi C, et al. Urine LOX-1 and Volatilome as Promising Tools Towards the Early Detection of Renal Cancer. Cancers (2021) 13(16):4213. doi: 10.3390/ cancers 13164213

144. Wilson SH, Chade AR, Feldstein A, Sawamura T, Napoli C, Lerman A, et al. Lipid-Lowering-Independent Effects of Simvastatin on the Kidney in Experimental Hypercholesterolaemia. Nephrol Dialysis Transplant (2003) 18(4):703-9. doi: 10.1093/ndt/gfg143

145. Wang R, Ding G, Liang W, Chen C, Yang H. Role of LOX-1 and ROS in Oxidized Low-Density Lipoprotein Induced Epithelial-Mesenchymal Transition of NRK52E. Lipids Health Dis (2010) 9:120. doi: 10.1186/1476-511X-9-120

146. Yang JD, Hainaut P, Gores GJ, Amadou A, Plymoth A, Roberts LR. A Global View of Hepatocellular Carcinoma: Trends, Risk, Prevention and Management. Nat Rev Gastroenterol Hepatol (2019) 16(10):589-604. doi: 10.1038/s41575-019-0186-y

147. Buechler C, Aslanidis C. Role of Lipids in Pathophysiology, Diagnosis and Therapy of Hepatocellular Carcinoma. Biochim Biophys Acta Mol Cell Biol Lipids (2020) 1865(5):158658. doi: 10.1016/j.bbalip. 2020.158658

148. Ni XC, Yi Y, Fu YP, Cai XY, Liu G, Huang JL, et al. Role of Lipids and Apolipoproteins in Predicting the Prognosis of Hepatocellular Carcinoma After Resection. OncoTargets Ther (2020) 13:12867-80. doi: 10.2147/ OTT.S279997 
149. Ooi K, Shiraki K, Sakurai Y, Morishita Y, Nobori T. Clinical Significance of Abnormal Lipoprotein Patterns in Liver Diseases. Int J Mol Med (2005) 15 (4):655-60. doi: 10.3892/ijmm.15.4.655

150. Jiang J, Nilsson-Ehle P, Xu N. Influence of Liver Cancer on Lipid and Lipoprotein Metabolism. Lipids Health Dis (2006) 5:4. doi: 10.1186/1476511X-5-4

151. Cho Y, Cho EJ, Yoo JJ, Chang Y, Chung GE, Jeong SM, et al. Association Between Lipid Profiles and the Incidence of Hepatocellular Carcinoma: A Nationwide Population-Based Study. Cancers (2021) 13(7):1599. doi: $10.3390 /$ cancers 13071599

152. Saito N, Sairenchi T, Irie F, Iso H, Iimura K, Watanabe H, et al. Low Serum LDL Cholesterol Levels are Associated With Elevated Mortality From Liver Cancer in Japan: The Ibaraki Prefectural Health Study. Tohoku J Exp Med (2013) 229(3):203-11. doi: 10.1620/tjem.229.203

153. Yan X, Yao M, Wen X, Zhu Y, Zhao E, Qian X, et al. Elevated Apolipoprotein B Predicts Poor Postsurgery Prognosis in Patients With Hepatocellular Carcinoma. OncoTargets Ther (2019) 12:1957-64. doi: 10.2147/OTT.S192631

154. Akkiz H, Carr BI, Guerra V, Donghia R, Yalçın K, Karaoğullarından U, et al. Plasma Lipids, Tumor Parameters and Survival in HCC Patients With HBV and HCV. J Trans Sci (2021) 7(3):421. doi: 10.15761/JTS.1000421

155. Koo SH. Nonalcoholic Fatty Liver Disease: Molecular Mechanisms for the Hepatic Steatosis. Clin Mol Hepatol (2013) 19(3):210-5. doi: 10.3350/cmh.2013.19.3.210

156. He M, Zhang W, Dong Y, Wang L, Fang T, Tang W, et al. Pro-Inflammation NF- $\kappa b$ Signaling Triggers a Positive Feedback via Enhancing Cholesterol Accumulation in Liver Cancer Cells. J Exp Clin Cancer Res (2017) 36(1):15. doi: 10.1186/s13046-017-0490-8

157. Asgharpour A, Cazanave SC, Pacana T, Seneshaw M, Vincent R, Banini BA, et al. A Diet-Induced Animal Model of non-Alcoholic Fatty Liver Disease and Hepatocellular Cancer. J Hepatol (2016) 65(3):579-88. doi: 10.1016/ j.jhep.2016.05.005

158. Hu Z, Zhang Z, Teng F, Feng J, Wu X, Chang Q. Role of Asxl2 in non -Alcoholic Steatohepatitis-Related Hepatocellular Carcinoma Developed From Diabetes. Int J Mol Med (2021) 47(1):101-12. doi: 10.3892/ijmm.2020.4782

159. Haberl EM, Pohl R, Rein-Fischboeck L, Höring M, Krautbauer S, Liebisch G, et al. Accumulation of Cholesterol, Triglycerides and Ceramides in Hepatocellular Carcinomas of Diethylnitrosamine Injected Mice. Lipids Health Dis (2021) 20(1):135. doi: 10.1186/s12944-021-01567-w

160. Bhat M, Skill N, Marcus V, Deschenes M, Tan X, Bouteaud J, et al. Decreased PCSK9 Expression in Human Hepatocellular Carcinoma. BMC Gastroenterol (2015) 15:176. doi: 10.1186/s12876-015-0371-6

161. Cheng SB, Liu HT, Chen SY, Lin PT, Lai CY, Huang YC. Changes of Oxidative Stress, Glutathione, and Its Dependent Antioxidant Enzyme Activities in Patients With Hepatocellular Carcinoma Before and After Tumor Resection. PloS One (2017) 12(1):e0170016. doi: 10.1371/journal.pone.0170016

162. Tian Y, Yang B, Qiu W, Hao Y, Zhang Z, Yang B, et al. ER-Residential NogoB Accelerates NAFLD-Associated HCC Mediated by Metabolic Reprogramming of oxLDL Lipophagy. Nat Commun (2019) 10(1):3391. doi: 10.1038/s41467-019-11274-X

163. Zhang D, Xi Y, Feng Y. Ovarian Cancer Risk in Relation to Blood Lipid Levels and Hyperlipidemia: A Systematic Review and Meta-Analysis of Observational Epidemiologic Studies. Eur J Cancer Prev (2021) 30(2):16170. doi: 10.1097/CEJ.0000000000000597

164. Onwuka JU, Okekunle AP, Olutola OM, Akpa OM, Feng R. Lipid Profile and Risk of Ovarian Tumours: A Meta-Analysis. BMC Cancer (2020) 20(1):200. doi: 10.1186/s12885-020-6679-9

165. Yarmolinsky J, Bull CJ, Vincent EE, Robinson J, Walther A, Smith GD, et al. Association Between Genetically Proxied Inhibition of HMG-CoA Reductase and Epithelial Ovarian Cancer. Jama (2020) 323(7):646-55. doi: 10.1001/ jama.2020.0150

166. Sun Y, Meng H, Jin Y, Shi X, Wu Y, Fan D, et al. Serum Lipid Profile in Gynecologic Tumors: A Retrospective Clinical Study of 1,550 Patients. Eur J Gynaecol Oncol (2016) 37(3):348-52.

167. Kim S, Lee M, Dhanasekaran DN, Song YS. Activation of Lxro/ $\beta$ by Cholesterol in Malignant Ascites Promotes Chemoresistance in Ovarian Cancer. BMC Cancer (2018) 18(1):1232. doi: 10.1186/s12885-018-5152-5

168. Zhu F, Xu X, Shi B, Zeng L, Wang L, Wu X, et al. The Positive Predictive Value of Low-Density Lipoprotein for Recurrence-Free Survival in Ovarian Cancer. Int J Gynaecol Obstetr (2018) 143(2):232-8. doi: 10.1002/ijgo.12645
169. Avall-Lundqvist EH, Peterson CO. Serum Cholesterol and Apolipoprotein B Levels may Reflect Disease Activity in Ovarian Cancer Patients. Acta Oncol (Stockholm Sweden) (1996) 35(8):1007-10. doi: 10.3109/ 02841869609100719

170. Pih GY, Gong EJ, Choi JY, Kim MJ, Ahn JY, Choe J, et al. Associations of Serum Lipid Level With Gastric Cancer Risk, Pathology, and Prognosis. Cancer Res Treat (2021) 53(2):445-56. doi: 10.4143/crt.2020.599

171. Ghahremanfard F, Mirmohammadkhani M, Shahnazari B, Gholami G, Mehdizadeh J. The Valuable Role of Measuring Serum Lipid Profile in Cancer Progression. Oman Med J (2015) 30(5):353-7. doi: 10.5001/ omj.2015.71

172. Singh PP, Singh S. Statins are Associated With Reduced Risk of Gastric Cancer: A Systematic Review and Meta-Analysis. Ann Oncol (2013) 24 (7):1721-30. doi: 10.1093/annonc/mdt150

173. Ma MZ, Yuan SQ, Chen YM, Zhou ZW. Preoperative Apolipoprotein B/ apolipoprotein A1 Ratio: A Novel Prognostic Factor for Gastric Cancer. OncoTargets Ther (2018) 11:2169-76. doi: 10.2147/OTT.S156690

174. Li C, Zhang J, Wu H, Li L, Yang C, Song S, et al. Lectin-Like Oxidized LowDensity Lipoprotein Receptor-1 Facilitates Metastasis of Gastric Cancer Through Driving Epithelial-Mesenchymal Transition and PI3K/Akt/Gsk3 $\beta$ Activation. Sci Rep (2017) 7:45275. doi: 10.1038/srep45275

175. Lu Y, Gentiluomo M, Lorenzo-Bermejo J, Morelli L, Obazee O, Campa D, et al. Mendelian Randomisation Study of the Effects of Known and Putative Risk Factors on Pancreatic Cancer. J Med Genet (2020) 57(12):820-8. doi: 10.1136/jmedgenet-2019-106200

176. Kok DE, van Roermund JG, Aben KK, den Heijer M, Swinkels DW, Kampman E, et al. Blood Lipid Levels and Prostate Cancer Risk; a Cohort Study. Prostate Cancer Prostatic Dis (2011) 14(4):340-5. doi: 10.1038/pcan.2011.30

177. Tsuchida T, Lee YA, Fujiwara N, Ybanez M, Allen B, Martins S, et al. A Simple Diet- and Chemical-Induced Murine NASH Model With Rapid Progression of Steatohepatitis, Fibrosis and Liver Cancer. J Hepatol (2018) 69(2):385-95. doi: 10.1016/j.jhep.2018.03.011

178. Iannelli F, Lombardi R, Milone MR, Pucci B, De Rienzo S, Budillon A, et al. Targeting Mevalonate Pathway in Cancer Treatment: Repurposing of Statins. Recent Patents Anti-cancer Drug Discovery (2018) 13(2):184-200. doi: 10.2174/1574892812666171129141211

179. Vallianou NG, Kostantinou A, Kougias M, Kazazis C. Statins and Cancer. Anti-cancer Agents Med Chem (2014) 14(5):706-12. doi: 10.2174/ 1871520613666131129105035

180. Kim MK, Myung SK, Tran BT, Park B. Statins and Risk of Cancer: A MetaAnalysis of Randomized, Double-Blind, Placebo-Controlled Trials. Indian J Cancer (2017) 54(2):470-7. doi: 10.4103/ijc.IJC_214_17

181. Ravnskov U. Re: The Association Between Statins and Cancer Incidence in a Veterans Population. J Natl Cancer Inst (2008) 100(13):972-3. author reply 3-4. doi: 10.1093/jnci/djn160

182. Kusama T, Mukai M, Iwasaki T, Tatsuta M, Matsumoto Y, Akedo H, et al. 3Hydroxy-3-Methylglutaryl-Coenzyme a Reductase Inhibitors Reduce Human Pancreatic Cancer Cell Invasion and Metastasis. Gastroenterology (2002) 122(2):308-17. doi: 10.1053/gast.2002.31093

183. Paragh G, Kertai P, Kovacs P, Paragh GJr., Fülöp P, Foris G. HMG CoA Reductase Inhibitor Fluvastatin Arrests the Development of Implanted Hepatocarcinoma in Rats. Anticancer Res (2003) 23(5a):3949-54.

184. Ahmadi Y, Karimian R, Panahi Y. Effects of Statins on the ChemoresistanceThe Antagonistic Drug-Drug Interactions Versus the Anti-Cancer Effects. Biomed Pharmacother $=$ Biomed Pharmacother $(2018)$ 108:1856-65. doi: 10.1016/j.biopha.2018.09.122

185. McKay RR, Lin X, Albiges L, Fay AP, Kaymakcalan MD, Mickey SS, et al. Statins and Survival Outcomes in Patients With Metastatic Renal Cell Carcinoma. Eur J Cancer (Oxford England: 1990) (2016) 52:155-62. doi: 10.1016/j.ejca.2015.10.008

186. Spampanato C, De Maria S, Sarnataro M, Giordano E, Zanfardino M, Baiano $\mathrm{S}$, et al. Simvastatin Inhibits Cancer Cell Growth by Inducing Apoptosis Correlated to Activation of Bax and Down-Regulation of BCL-2 Gene Expression. Int J Oncol (2012) 40(4):935-41. doi: 10.3892/ijo.2011.1273

187. Ahmadi Y, Ghorbanihaghjo A, Argani H. The Balance Between Induction and Inhibition of Mevalonate Pathway Regulates Cancer Suppression by Statins: A Review of Molecular Mechanisms. Chem-Biol Interact (2017) 273:273-85. doi: 10.1016/j.cbi.2017.06.026 
188. Patel KK, Kashfi K. Lipoproteins and Cancer: The Role of HDL-C, LDL-C, and Cholesterol-Lowering Drugs. Biochem Pharmacol (2021) 196:114654. doi: 10.1016/j.bcp.2021.114654

Conflict of Interest: The authors declare that the research was conducted in the absence of any commercial or financial relationships that could be construed as a potential conflict of interest.

Publisher's Note: All claims expressed in this article are solely those of the authors and do not necessarily represent those of their affiliated organizations, or those of the publisher, the editors and the reviewers. Any product that may be evaluated in this article, or claim that may be made by its manufacturer, is not guaranteed or endorsed by the publisher.

Copyright () 2022 Deng, Zhu, Zhao, Li, Gu, Liao and Qin. This is an open-access article distributed under the terms of the Creative Commons Attribution License (CC BY). The use, distribution or reproduction in other forums is permitted, provided the original author(s) and the copyright owner(s) are credited and that the original publication in this journal is cited, in accordance with accepted academic practice. No use, distribution or reproduction is permitted which does not comply with these terms. 